\title{
GEOLOGIA E GEOQUÍMICA DA MINERALIZAÇÃO DE CU-Au PRIMÁRIA DA MINA DE Au DO IGARAPÉ BAHIA, SERRA DOS CARAJÁS
}

\author{
ZARA GERHARDT LINDENMAYER*, LUIZ HENRIQUE RONCHI* \& JORGE HENRIQUE LAUX*
}

\begin{abstract}
THE IGARAPÉ BAHIA GOLD MINE, SERRA DOS CARAJÁS, PARÁ: GEOLOGY AND GEOCHEMISTRY OF THE PRIMARY Cu-Au SULFIDE ORE Chalcopyrite and pyrite are the primary sulfides in the southernmost part of the Bahia gold Mine. They occur either in veins or'disseminatedin all rock types. Gold was found solely associated with a few chalcopyrite crystals. The sulfide host rocks comprise conformable metasandstones and siltstones, metabasalts and a granophyric gabbro, whose contacts are delimitated by a mineralyzed hydraulic breccia. There is an intense hydrothermal alteration associated with the ore. Chlorite (Fe-chlinoclore) is the most important alteration mineral, occurring associated to albite, calcite, quartz and turmaline. Mass balance calculations on granophyric gabbro indicate that the hydrothermal alteration took place with small $(2 \%)$ volume increase. Due to this, $\mathrm{SiO}_{2}(+2.88$ to $+7.65 \%), \mathrm{MgO}(+0.87$ to $+1.16 \%), \mathrm{U}(+7.91$ to $+9.13 \%)$ were gained and $\mathrm{CaO}(-6.39$ to $-6.60 \%), \mathrm{Al}_{2} \mathrm{O}_{3}(-1.88$ to $-3.52 \%), \mathrm{K}_{2} \mathrm{O}(-0.8 \%)$ and $\mathrm{Na}_{2} \mathrm{O}(-0.54$ to $-0.93 \%)$ were lost by the rocks . The sulfide host rocks are enriched in LREE, U, Kb, F and Cl, together with $\mathrm{Cu}, \mathrm{Au}, \mathrm{Ag}$, Mo. They also show good correlation between $\mathrm{Mo}-\mathrm{Pb}(0.913), \mathrm{Ag}-\mathrm{Mo}$ $(0.794)$ and $\mathrm{Ag}-\mathrm{Pb}(0.782)$, strongly suggesting that highly saline (up to $40 \% \mathrm{wt}$. eq. $\mathrm{NaCl}$ ) crustal fluids, probably derived from granitic rocks, played an important role during mineralization. Similar influence was described in Salobo $\mathrm{Cu}(\mathrm{Au}-\mathrm{Mo})$ and Pojuca $\mathrm{Cu}(\mathrm{Zn})$ deposits, that are correlated to hydrothermal systems related to the emplacement of Mesoproterozoic anorogenic granites. The hydrothermal system underwent decreasing temperature from 500 to $100^{\circ} \mathrm{C}$, according to the homogenization temperatures (HT) determined in multiphasic fluid inclusions in quartz. The widespread chloritization occurred at $270^{\circ} \mathrm{C}$, estimated by the chlorite geothermometer, as well as by the fluid inclusions data.

Keywords: Hydrothermal alteration, fluid inclusions, granite-related fluids.

RESUMO No extremo sul do corpo mineralizado da Mina de Au do Igarapé Bahia, a mineralização sulfetada primária, disseminada e venular, composta por calcopirita e pinta, apresenta o Au associado à calcopirita. As rochas hospedeiras da mineralização compreendem um pacote de meta arenitos e meta ritmitos, metabasaltos toleíticos e uma intrusão gábrica granofírica. Esta última, colocada entre as rochas metassedimentares e os metabasaltos, é balizada por brechas hidráulicas. A mineralização distribui-se tanto nas rochas sedimentares quanto ígneas, embora o sulfeto venular, mais importante, ocorra principalmente em zonas de uma brecha hidráulica. A mineralização está associada a uma intensa alteração hidrotermal. As assembléias minerais, predominantes em todos os tipos de rochas da área, consistem de clorita

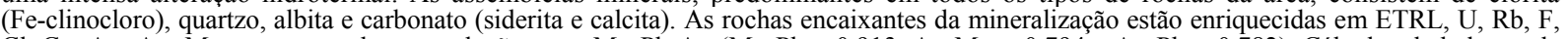
$\mathrm{Cl}, \mathrm{Cu}, \mathrm{Au}, \mathrm{Ag}$, Mo, e mostram boa correlação entre Mo-Pb-Ag (Mo-Pb =0,913, Ag-Mo =0,794 e Ag-Pb =0,782). Cálculos de balanço de massa efetuados a partir da alteração de uma assembléia anfibolítica Pará uma clorítica, no gabro granofírico, indicam que a alteração hidrotermal ocorreu com um aumento de volume de $2 \%$, quando houve ganhos significativos de $\mathrm{SiO}_{2}(+2,88$ a $+7,65 \%), \mathrm{MgO}(+0,87$ a $+1,16 \%)$, U ( +7,91 $\mathrm{a}+9,13 \%)$ e perdas de $\mathrm{CaO}(-6,39$ a $-6,60 \%), \mathrm{Al}_{2} \mathrm{O}_{3}(-1,88$ a $-3,52 \%), \mathrm{K}_{2} \mathrm{O}(-0,8 \%)$ e $\mathrm{Na}_{2} \mathrm{O}(-0,54$ a $-0,93 \%)$. O sistema hidrotermal responsável pela mineralização continha fluidos altamente salinos (até $40 \%$ eq. peso $\mathrm{NaCl}$ ) e ácidos, provavelmente de contribuição crustal, e provenientes de fonte granítica, à semelhança dos depósitos de $\mathrm{Cu}(\mathrm{Au}-\mathrm{Mo})$ do Salobo e $\mathrm{Cu}-(\mathrm{Zn})$ do Pojuca. O sistema metamórfico e hidrotermal evoluiu ao longo de um amplo intervalo de temperaturas $\left(500-100^{\circ} \mathrm{C}\right)$ e a cloritização generalizada ocorreu a $270^{\circ} \mathrm{C}$, de acordo com o geotermômetro da clorita e com a variação das temperaturas de homogeneização das inclusões multifásicas em quartzo.

Palavras chave: Alteração hidrotermal, inclusões fluidas, fluidos graníticos
\end{abstract}

INTRODUÇÃO Este trabalho visa contribuir Pará uma melhor compreensão dos processos de alteração hidrotermal responsáveis pela mineralização sulfetada primária da Mina de Au do Igarapé Bahia, a partir da qual se originou o depósito secundário de $\mathrm{Au}$, atualmente em exploração.

A Mina situa-se na Serra dos Carajás, $45 \mathrm{~km}$ a oeste da Mina de Ferro do N4, e constitui hoje a principal unidade de produção de $\mathrm{Au}$ da Companhia Vale do Rio Doce, de onde foram extraídas 1 O toneladas do mPará em 1995 (Alves \& Brito 1996). O ouro ocorre em uma zona

laterítica desenvolvida sobre um depósito de cobre primário sulfetado de baixo teor (Docegeo 1988), com valores médios de $\mathrm{Cu}$ em torno de $0,3 \%$ (Althoff et al 1994).

A ocorrência de cobre do Igarapé Bahia, descoberta pela DOCEGEO em 1974, foi inicialmente descrita como um depósito de cobre sedimentar, hospedado em siltitos e arenitos (Hirata Pará. 1982). Ferreira Filho (1985) descreveu a geologia do depósito e relacionou a mineralização, classificada como stringer ore, à uma seqüência vulcano-sedimentar hidrotermalmente alterada, formada entre o final do Arqueano e o início do Paleo-Proterozóico. O magmatismo basáltico foi caracterizado como toleiítico e continental por Sachs (1993). Estudos de inclusões fluidas (Ribeiro \& Villas 1986, Althoff Pará. 1994, Zang \& Fyfe 1993, Zang \& Fyfe 1995) identificaram dois tipos distintos de fluidos relacionados à alteração hidrotermal, um mais antigo de baixa salinidade associado à espilitização, e outro mais jovem e altamente salino, atribuído à influência granítica. Os processos de mineralização de ouro laterítico foram estudados por Zang \& Fyfe (1993) Angélica Pará. (1996) e Costa \& Angélica (1996).

Todavia, a área ainda carece de estudos visando especificamente os processos de alteração hidrotermal relacionados à concentração dos sulfetos primários e ouro, aqui estudados. São apresentados pela primeira vez: os diversos tipos de rochas máficas com suas relações espaciais, temporais e assinaturas geoquímicas; a quantificação dos processos de alteração e sua relação com a composição e temperatura dos fluidos mineralizantes.

CONTEXTO GEOLÓGICO As rochas da área estudada pertencem ao Grupo Igarapé Bahia, unidade superior do Supergrupo
Itacaiúnas, definido pela Docegeo (1988) na Serra dos Carajás (Fig. D.

$\mathrm{O}$ embasamento da região, onde repousa discordantemente o Supergrupo Itacaiúnas, é formado por gnaisses tonalíticos e trondhjemíticos do Complexo Xingu (Silva Pará. 1974), datados de 2.859+/- 2 Ma (U/Pb, Machado Pará. 1991).

O Supergrupo Itacaiúnas compreende três grupos. O Grupo Igarapé Salobo-Pojuca (Docegeo 1988), basal, é composto por anfibolitos, formações ferríferas e quartzitos. O Grupo Grão Pará (Beisiegel Pará 1973), sobreposto ao primeiro, é formado por três unidades. A inferior (Grupo Paráuapebas, Docegeo 1988) é constituída por rochas vulcânicas bimodais (Gibbs Pará. 1986), de afiliação controvertida devido à intensa alteração hidrotermal (Lindenmayer Pará. 1996) e datadas de 2.759 +/- 2 Ma (U/Pb Machado Pará. 1991); a intermediária (Formação Carajás, Beisiegel Pará. 1973), é composta por formações ferríferas bandadas, e a superior compreende rochas vulcânicas (Beisiegel Pará. 1973, Docegeo,1988). O Grupo Igarapé Bahia corresponde a unidade superior do Supergrupo Itacaiúnas, sendo formado por rochas metassedimentares, metavulcanoclásticas, intrusivas e metavulcânicas básicas (Docegeo 1988). Ele não aflora e restringe-se à área da Mina, tendo sido descrito a partir de furos de sondagem.

As rochas sedimentares do Grupo Águas Claras (Araújo \& Maia 1991), anteriormente denominado de Grupo Rio Fresco (Docegeo 1988), são tidas como sobrepostas às do Grupo Bahia (Docegeo 1988), embora as relações estratigráficas entre ambos grupos (Igarapé Bahia e Águas Claras) sejam ainda controversas.

Sills de diabásio colocados em pequena profundidade, conforme indicado pela textura granofírica, são freqüentes na área, tendo sido descritos cortando as rochas do Grupo Igarapé Bahia, (sul datado de $2.577+/-72 \mathrm{Ma}, \mathrm{Rb} / \mathrm{Sr}$ - rocha total, Ferreira Filho 1985), os arenitos do Grupo Águas Claras (Barros Pará. 1994 - sill datado de 2.645 +/$12 \mathrm{Ma}, \mathrm{Pb} / \mathrm{Pb}$ em zircão, Dias Pará. 1996), e as formações ferríferas da Formação Carajás na Serra Norte (Teixeira \& Eggler 1994) e na Serra Sul (Lindenmayer \& Laux, em preParáção).

Granitos deformados tais como Salobo, Estrela e Itacaiúnas, de idades $\approx 2.5$ Ga, (Machado Pará. 1991, Barros \& Dali'Agnol $1992 \mathrm{e}$ 
Souza Pará 1996) e granitos anorogênicos de idades $\approx 1.9 \mathrm{Ga}$ (Machado Pará. 1991) cortam as rochas anteriormente descritas.

MÉTODOS DE TRABALHO A área estudada restringe-se ao extremo sul do corpo mineralizado do Igarapé Bahia, onde foram efetuadas descrições de $1695 \mathrm{~m}$ de testemunhos de sondagem, seguidas da elaboração do perfil correspondente (LT 00). Este estudo baseia-se ainda na petrografia dos minerais de minério e das rochas hospedeiras e encaixantes da mineralização sulfetada (70 amostras), em estudos de inclusões fluidas em quartzo de rochas granofíricas, em análises químicas de silicatos por microssonda eletrônica, análises químicas de elementos maiores, traços e ETR em rochas encaixantes da mineralização (23 amostras), e em análises de elementos traços (30 amostras) executadas em rochas hospedeiras.

Foram analisados por fluorescência de Raios- $\mathrm{X} \mathrm{SiO}_{2}, \mathrm{Al}_{2} \mathrm{O}_{3}, \mathrm{CaO}$, $\mathrm{TiO}_{2}, \mathrm{Fe}_{2} \mathrm{O}_{3}, \mathrm{P}_{2} \mathrm{O}_{5}, \mathrm{U}, \mathrm{Th}, \mathrm{Ba}, \mathrm{Mo}, \mathrm{Rb}$ e Sr; por Absorção Atômica $\mathrm{MnO}, \mathrm{K}_{2} \mathrm{O}, \mathrm{Na}_{2} \mathrm{O}, \mathrm{Zn}, \mathrm{Au}, \mathrm{Ag}$ e $\mathrm{Pb}$ e por Espectrometria de Emissão Optica (EOS) $\mathrm{MgO}, \mathrm{Cu}, \mathrm{Ni}, \mathrm{B}, \mathrm{Cr}, \mathrm{As}, \mathrm{Y}$ e Zr. F e Cl foram determinados pelo método do íon seletivo, os ETR por Espectrometria de Emissão por Plasma (ICP) e o $\mathrm{FeO}$ por titulação, no laboratório da Geosol, em Belo Horizonte.

Pará os cálculos de balanço de massa, a densidade das rochas foi determinada pelo método do picnômetro, em amostras Paráfinadas, nos laboratórios da UNISINOS.

As análises dos cristais de clorita foram realizadas na microssonda eletrônica marca JEOL, modelo Super Probe 733, dos laboratórios da Companhia Vale do Rio Doce - SUTEC, em Minas Gerais. Foi utilizada a voltagem de excitação de $15 \mathrm{KV}$, tempo de análise de $10 \mathrm{~s}$ e corrente de 15 ๆA.. O limite de detecção do equipamento é de 1000 ppm, e o erro analítico de aproximadamente $2 \%$. Os padrões utilizados consistiram em minerais naturais e vidros sintéticos

$\mathrm{O}$ estudo microtermométrico das inclusões fluidas foi efetuado no laboratório de petrografia da UNISINOS, com platina Chaix Meca (Poty Pará. 1976) instalada em microscópio Olympus BH2. A reprodutibilidade das medidas é de aproximadamente $0,2^{\circ} \mathrm{C}$. A curva de calibração foi construída a partir de dados obtidos com inclusão fluida natural rica em $\mathrm{CO}_{2}$ puro $\left(-56,6^{\circ} \mathrm{C}\right)$, água desmineralizada $\left(0,0^{\circ} \mathrm{C}\right)$ e produtos MERCK indicadores de temperatura $\left(40,0^{\circ} \mathrm{C}, 100,0^{\circ} \mathrm{C}\right.$, $135,0^{\circ} \mathrm{C}, 200,0^{\circ} \mathrm{C}, 306,8^{\circ} \mathrm{C}$ e $398,0^{\circ} \mathrm{C}$ ). Foram confeccionadas lâminas bipolidas com espessura em torno de 0,3 a $0,5 \mathrm{~mm}$, coladas a frio com Entelan e descoladas com Xylol (Merck art. 8687) Pará evitar alterações devidas à preParáção das amostras. Os cálculos de salinidade, densidade, isócoras e estimativas de pressão foram realizadas utilizando o programa MacFlinCor (Brown \& Hagemann 1994).

$\mathrm{O}$ código empregado Pará identificar as amostras utilizadas corresponde ao número do furo de sondagem, seguido da profundidade de coleta.

GEOLOGIA DO DEPÓSITO O Grupo Igarapé Bahia consiste de duas unidades: Formação Grota do Vizinho basal, e Formação Sumidouro (Docegeo 1988). A Formação Grota do Vizinho, hospedeira da mineralização sulfetada, é formada por uma seqüência de rochas sedimentares, pelitos e ritmitos, e piroclásticas ácidas a intermediárias, onde se intercalam rochas básicas, representadas por lavas basálticas e intrusões de diabásio e microgabros. A Formação Sumidouro é representada por arenitos arcosianos, contendo intercalações de rochas vulcânicas básicas (Docegeo 1988).

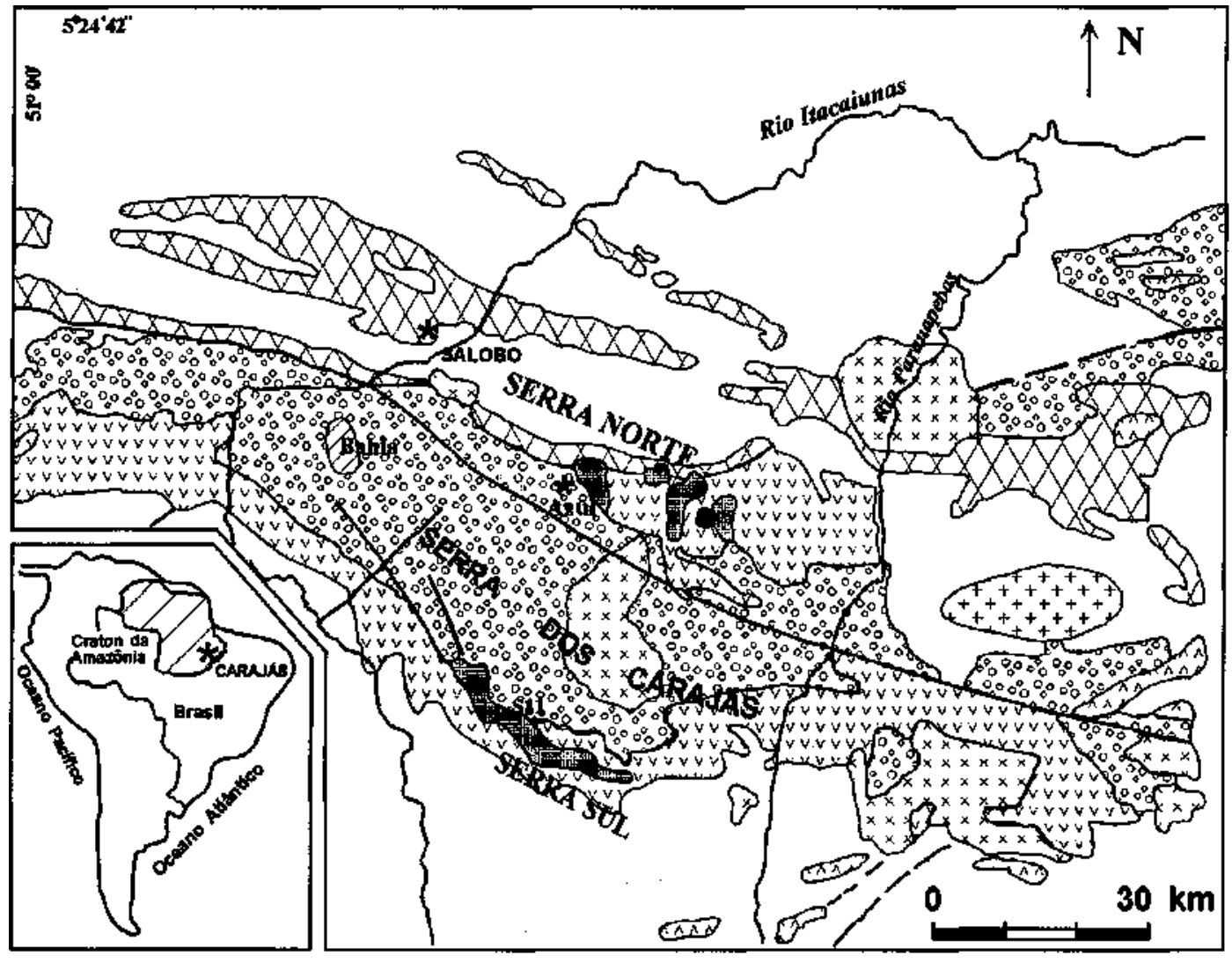

[x: Granitos Anorogenicos

Fog Formaçato Aguas Claras

\section{Granitos Arqueanos}

Intrusivas Básicas

Embasamento - Complexo Xingú
Grupo lgarapé Bahia

Grupo Grăo Paráformaçăo Carajás

Qv. Grupo Grăo Pará-Formação Parauapebas

$\triangle$ Grupo Igarape Salobo-Pojuca

Falhas

Figura 1- Mapa geológico regional.(Modificado de Docegeo 1988). 
A geologia do depósito (Seção $300 \mathrm{NW}$ ) foi descrita anteriormente por Ferreira Filho (1985). A descrição apresentada a seguir, corresponde à geologia do extremo sul do corpo mineralizado da Mina do Igarapé Bahia (Seção LT 00, Figura 2), onde se observam duas unidades principais, ambas de direção NNW e portadoras de mineralização sulfetada.

A primeira unidade ocorre no topo do perfil. Ela é predominantemente sedimentar e correlacionável à Formação Sumidouro, sendo composta por rochas metassedimentares elásticas terrígenas, intrudidas por pequenas lentes gabróicas granofíricas, uma delas com o topo delimitado por uma zona de brecha. Na base desta unidade observa-se uma camada pouco espessa de formação ferrífera brechada. A sul da seção estudada ocorrem intercalações de formação ferrífera bandada no pacote de ritmitos.

A segunda unidade, basal e possivelmente correlacionável à Formação Grota do Vizinho, é composta por rochas vulcânicas máficas de textura sub-ofítica fina, sotoposta a uma intrusão gabróide, cujos contatos são concordantes com as encaixantes. O sill gábróico possui textura granofírica média a grossa, encontra-se intensamente alterado, e seus contatos encontram-se balizados por zonas de brecha hidráulica, freqüentemente carbonatizadas. A presença de calcita-clorita-xistos marca zonas de cisalhamento, intensamente alteradas e carbonatizadas, no interior do sill gábróico.

Um dique de diabásio fresco, portador de textura ofítica média, corta a unidade sedimentar superior e o sill gábrico.

Rochas sedimentares As rochas sedimentares elásticas terrígenas, observadas na unidade superior, são representadas por metaconglomerados, arenitos (médios a grossos) e ritmitos, sendo os dois últimos os mais freqüentes. De uma maneira geral estas rochas compõem vários ciclos granodecrescentes ascendentes. Cada um destes ciclos inicia com conglomerados que gradam verticalmente Pará arenitos maciços ou com gradação normal, encerrando com ritmitos. Os arenitos conglomeráticos e arenitos grossos, que predominam a SW, dão lugar em direção NE, a um pacote de ritmitos, indicando aprofundamento da bacia nesta direção.

Os metarenitos são formados por grãos de quartzo imersos em matriz de clorita, albita, mica branca e turmalina.

Também ocorrem nos ritmitos intercalações de formação ferrífera bandada óxido-carbonato. Elas são compostas por bandas alternadas de magnetita, quartzo e siderita.

$\mathrm{Na}$ base do pacote sedimentar elástico foi observada uma brecha aparentemente estratiforme, onde os fragmentos de formação ferrífera finamente bandada são cimentados por magnetita.
Rochas Vulcânicas Máficas As rochas vulcânicas máficas correspondem a unidade basal. Elas são pobremente representadas na seção estudada, correspondendo a rochas basálticas, cujos contatos com o sill granofírico são marcados por zonas de brecha. A elas também intercalam-se faixas e lentes brechadas. Os metabasaltos possuem textura sub-ofítica fina e coloração cinza esverdeada, sendo compostos por anfibólio e clorita $60-65 \%$; plagioclásio $25-30 \%$; quartzo $1-2 \%$, calcopirita, magnetita e ilmenita $1-2 \%$; e traços de carbonatos, epidoto, estilpnomelano e mica branca.

Microscopicamente os máficos formam pseudomorfos multi ou unicristalinos do antigo piroxênio $(0,5-0,6 \mathrm{~mm})$, compostos por: anfibólio pleocróico de verde azulado escuro a verde amarelado (actinolita), prismático, com bordos esfiapados, apresentando inclusões de leucoxênio e calcopirita em fina poeira, ao longo dos planos de clivagem; ou clorita, em indivíduos de 0,1 a $0,2 \mathrm{~mm}$ com inclusões esquelParás de ilmenita e magnetita. O plagioclásio prismático é subidioblástico $(0,1-0,2 \mathrm{~mm})$ e turvo, mostrando faces basais irregulares e geminação albita, estando alterado Pará mica branca. Em assembléias portadoras de clorita ele é albita $\left(\mathrm{An}_{1-4}\right)$. O plagioclásio associado à actinolita é oligoclásio. Em zonas restritas nota-se o aparecimento de uma xistosidade incipiente, dada pelo aparecimento da biotita marrom-verde, orientada e muito fina $(0,1-0,2 \mathrm{~mm})$. Observam-se também agregados arredondados de epidoto, siderita e calcopirita, cercados por zonas de carbonatização incipiente.

Intrusão Granofírica As lentes de gabro granofírico, concordantes com a unidade sedimentar, na seção estudada, indicam a presença de um sill, tal como ocorre no depósito de Au de Águas Claras. Os contatos do sill granofírico, tanto com as rochas vulcânicas máficas, como com a unidade sedimentar, se verificam através de espessa zona de brecha hidrotermal/hidráulica, que é também encontrada, menos freqüentemente, intercalada nas rochas granofíricas.

O gabro granofírico é uma rocha maciça, de cor verde com pontuações brancas e textura granoblástica média, formado por clorita e/ou anfibólio (39-56\%); plagioclásio (14-35\%) e quartzo (20-27\%), além de titanita, fluorita, calcopirita, pirita, magnetita e ilmenita (2-3\%). Foram observadas duas assembléias minerais distintas nestas rochas. Uma de mais alta temperatura, menos hidratada e considerada como proveniente de um processo metamórfíco, é composta por hornblendaactinolita, oligoclásio, quartzo, turmalina, magnetita-ilmenita e epidoto. A outra, posterior a primeira, de mais baixa temperatura $(270 \mathrm{a}$ $170^{\circ} \mathrm{C}$, Lindenmayer \& Laux, em preParáção) e proveniente de alteração hidrotermal, é formada por clorita, quartzo, albita, titanita, hematita, fluorita, carbonatos, mica branca, calcopirita e pirita.

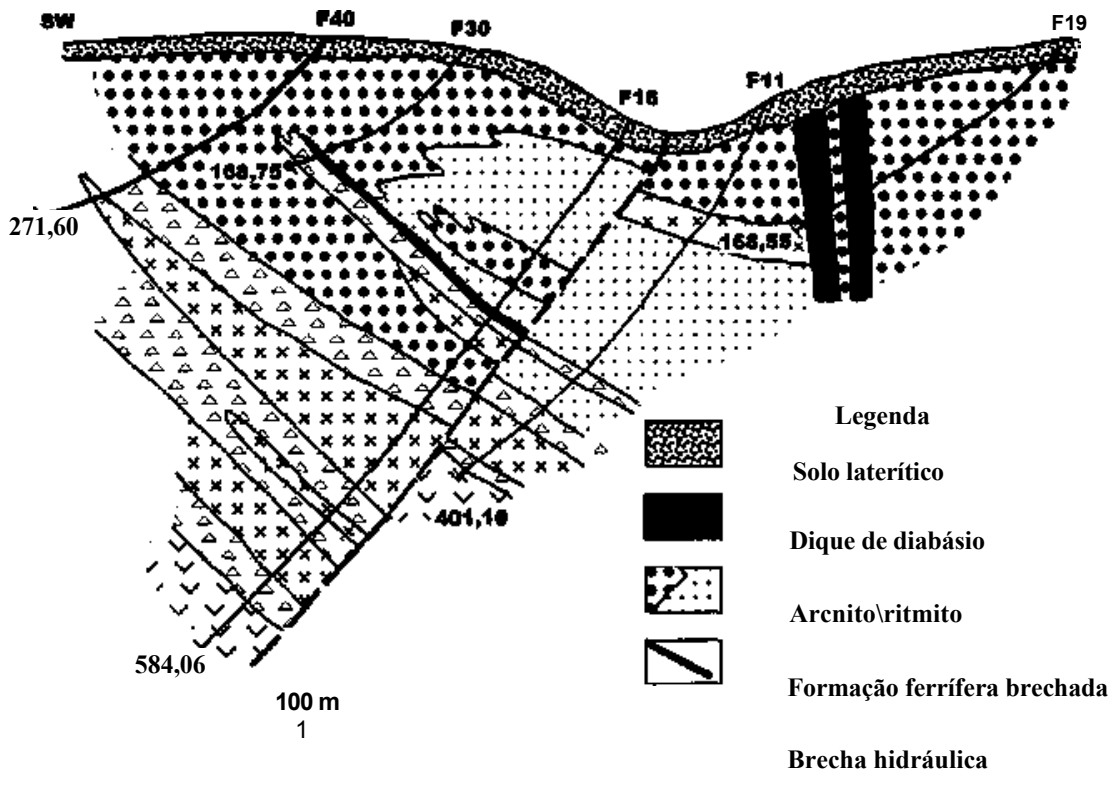

Gabro granofírico

Mctabasalto

Falha inferida 
Microscopicamente observa-se uma matriz composta por palhetas de clorita (Fe-clinocloro, $\mathrm{Fe} / \mathrm{Fe}+\mathrm{Mg}=0,37-0,40)$ (Tabela 1), muito pequenas $(0,1-0,2 \mathrm{~mm})$, ou actinolita $(0,1-1,5 \mathrm{~mm})$, ambas sem orientação preferencial e ocasionalmente pseudomórficas do piroxênio original. Nesta matriz distribuem-se ainda biotita marrom-castanho $(0,01-0,5 \mathrm{~mm})$, parcialmente substituída por clorita, além de zircão, fluorita e allanita. Cristais prismáticos de plagioclásio $(0,1-2 \mathrm{~mm})$ (ou apenas os seus fantasmas) destacam-se por suas dimensões dos demais minerais constituintes da matriz. Eles possuem geminação albita, são turvos e parcialmente substituídos por epidoto, carbonato e mica branca. O plagioclásio mostra ainda intercrescimentos vermiculares com o quartzo, em forma de coroas, em torno dos antigos cristais euédricos. Estes intercrescimentos granofíricos são observados também em zonas de forma grosseiramente triangular, tanto na matriz clorítica como naquela portadora de anfibólio. Isto indica resfriamento rápido e cristalização do magma residual no ponto eutético, sendo freqüente em intrusões rasas que foram submetidas a uma perda rápida de voláteis, conforme referido por Shelley (1992). Albita límpida, proveniente do processo de alteração, forma coroas em continuidade óptica com o plagioclásio alterado, (oligoclásio-andesina) no granófiro anfibolítico. No granófiro cujo mineral máfico é clorita, o plagioclásio é albita. O quartzo, além de constituir as vermículas intercrescidas com o plagioclásio, ocorre em cristais individuais irregulares. Ele comumente possui formas esquelParás ou arredondadas, distribuídas ao longo de planos de clivagem do plagioclásio. Em casos extremos, o quartzo chega a substituir completamente o plagioclásio, indicando a existência de um processo de silicificação. A calcopirita é intersticial à clorita, exibindo formas irregulares $(0,01-0,5 \mathrm{~mm})$, junto com ilmenita, hematita e magnetita esquelParás. As relações texturais descritas indicam que a intrusão gábrica, tal como os metabasaltos sofreu um processo de cloritização, albitização e silicificação, posterior a formação da assembléia actinolita-oligoclásio.

Brecha hidráulica Estas brechas são muito importantes porque nelas ocorrem as principais mineralizações sulfetadas primárias, na seção estudada da Mina do Igarapé Bahia. Referências à associação da mineralização com brechas são encontradas em Ferreira Filho (1985), Docegeo (1988) e Althoff Pará (1994).

A brecha hidráulica ocorre preferencialmente nos contatos da intrusão granofírica, tanto com as rochas sedimentares quanto com as meta vulcânicas, sendo também observada em intercalações, dentro do gabro granofírico e da unidade metavulcânica máfica. Os contatos entre as brechas e as rochas encaixantes são gradacionais, com a zona de brecha gradando Pará rochas fraturadas e venuladas. Muitas vezes o cimento calcítico da brecha avança sobre a rocha adjacente.

As brechas hidráulicas são rochas compostas por fragmentos angulosos a subangulosos, de dimensões variáveis entre 0,4 e $3 \mathrm{~cm}$, de bordos muitas vezes corroídos e cortadas por diversas gerações de fraturas e veios. Os fragmentos são locais e derivados das rochas imediatamente adjacentes. Em geral são monolitológicos representados pela rocha granofírica, ritmitos ou metabasaltos. Mais raramente são bi ou trilitológicos, mostrando fragmentos de formação ferrífera, chert, quartzo e plagioclásio. $\mathrm{O}$ preenchimento interfragmentar é formado por matriz clorítica ou cimento calcítico. A matriz clorítica é provavelmente formada em substituição a materiais mais antigos. À clorita se associam magnetita, siderita e calcita. Cavidades vazias são freqüentes na matriz. O cimento carbonático possui composição calcítica, sendo formado por uma rede de veios com estrutura em mosaico que tornam-se mais espessos à medida que se afastam da rocha encaixante. Intensa venulação por quartzo é observada nestas brechas, chegando em alguns pontos a apresentar $20-30 \%$ de seu volume. Magnetita e hematita podem ocupar as bordas destes veios, junto com turmalina e calcopirita. Ocorrem ainda veios de calcita-turmalina, a última em prismas radiados, e quartzo-calcita. A calcita e a clorita geralmente substituem, respectivamente, o quartzo e a turmalina nos veios. Nestas zonas de brecha hidráulica são freqüentes as fraturas abertas, atapetadas por quartzo bipiramidado euédrico, junto com óxidos de Mn de hábito botrioidal.

Há ainda um nível de brecha de composição peculiar, que ocorre na base da unidade sedimentar, sobreposta a uma lente granofírica. Esta brecha é constituída por fragmentos de formação ferrífera, cimentados por magnetita. Ela é cortada por veios de quartzo e siderita, portadores de calcopirita.

\section{Calcita-clorita-turmalina-xistos}

Os calcita-clorita-turmalina-xistos ocorrem próximos das zonas de contato do sul granofírico, possivelmente representando zonas de cisalhamento onde a alteração hidrotermal, tanto do sill como dos metabasaltos, foi muito intensa. Seus contatos com as rochas encaixantes se verificam por meio de urna zona de carbonatização crescente, que culmina com a zona foliada e carbonatizada, aqui denominada de calcita-clorita-turmalinaxisto. A carbonatização, quando incipiente, tanto no metabasalto como no granófiro, é representada por siderita, enquanto que a calei- tá predomina nas zonas de carbonatização volumetricamente importantes. Os calcita-clorita-turmalina-xistos chamam a atenção pela presença de lentículas de calcita, que atingem até $3 \mathrm{~cm}$ ao longo do eixo maior, circundadas por palhetas de clorita, junto com quartzo e turmalina, este último mineral encontra-se parcialmente substituído por clorita. A calcita é o último mineral de alteração a se formar nestas rochas, pois ela corrói o quartzo e substitui parcialmente a clorita.

Dique de diabásio Um dique de diabásio corta a unida-de sedimentar na porção NE do perfil estudado, formando dois segmentos de largura aparente de 40-50 metros que podem, possivelmente, representar bifurcações de um dique mais possante. Este dique colocou-se após os efeitos da alteração hidrotermal, pois ele se encontra muito pouco alterado.

O dique é de um diabásio cinza esverdeado, isótropo e de granulação média, onde se observam cristais de plagioclásio branco (42$61 \%$ ) e piroxênio verde (30-55\%) num arranjo ofítico. Amígdalas preenchidas por clorita ocorrem nas margens de resfriamento, encontradas nas zonas de contato com as encaixantes.

Microscopicamente se observam grandes cristais de piroxênio augítico englobando ripas de plagioclásio geminado. O piroxênio mostra substituição incipiente por anfibólio pleocróico de verde escuro a azulado (hastingsita-pargasita?), o qual, por sua vez, é circundado por anfibólio mosqueado incolor e verde (cummingtonita?) e clorita. O plagioclásio também apresenta substituição incipiente por mica branca.

MINERALIZAÇÃO SULFETADA A mineralização sulfetada, formada por calcopirita e pirita, com calcosita e covelita subordinadas, constitui os dois tipos principais de minério primário encontrados no extremo sul do corpo mineralizado da Mina de Au do Igarapé Bahia, que são o disseminado e o venular, conforme já descrito por Ferreira Filho (1985) e Althoff Pará (1994).

$\mathrm{O}$ minério disseminado distribui-se em todos os tipos litológicos anteriormente descritos. O minério venular, embora também ocorra em todos os tipos de rocha da área, concentra-se principalmente nas zonas de brechas hidráulicas.

O minério disseminado, nas rochas sedimentares, pode ser subdividido nos tipos finamente disseminado e nodular. $\mathrm{O}$ minério finamente disseminado compreende predominantemente pirita $(0,01$ a 0,04 $\mathrm{mm}$ ) possuindo formas irregulares dispersas na matriz clorítica dos arenitos. $\mathrm{O}$ minério nodular ocorre principalmente nos ritmitos, sob forma de nódulos lenticulares Parálelos à laminação, sempre localizados nos leitos de granulação mais grossa. Consiste em calcopirita e subordinadamente pirita, em agregados cujo eixo maior varia entre 1,0 a $1,5 \mathrm{~cm}$ e o menor entre 0,3 a $0,5 \mathrm{~cm}$. Estes nódulos encontram-se sempre envolvidos por uma capa de clorita, sendo muito freqüente a presença de microvênulas de clorita ligando dois nódulos contíguos.

Nos metabasaltos e gabros granofíricos a calcopirita ocorre como fina poeira ao longo dos antigos planos de clivagem do piroxênio ou como disseminações junto à matriz clorítica, em cristais individuais de 0,02 a $0,03 \mathrm{~mm}$.

O ouro foi encontrado, dentro dos limites de detecção do método analítico, em 3 cristais de calcopirita (Bocalon 1 997). O minério venular foi dParáhadamente descrito por Althoff et al. (1994).

Os veios que interceptam as rochas máficas e metassedimentares sempre possuem as bordas atapetadas por clorita, nas quais os planos de clivagem são perpendiculares às paredes. Estes veios, de espessuras variáveis entre 0,7 e $2,5 \mathrm{~cm}$, são compostos por calcita-quartzo-calcopirita, quartzo-magnetita-calcopirita e quartzo-calcopirita. Podem ocorrer substituições parciais da calcopirita por pirita, bornita e calcosita.

Repetidas gerações de veios cortam a zona de brecha hidráulica. Os mais antigos são compostos por siderita e calcopirita, sendo seguidos por veios de quartzo-calcita-turmalina e quartzo turmalina. Estes veios parecem hospedar preferencialmente a mineralização sulfetada da área.

Molibdenita e digenita foram descritas na área por Althoff et al. (1994), enquanto que uraninita foi observada por Angélica et al. (1996).

A sucessão Parágenética dos minerais descritos encontra-se representada na figura 3 . 
Tabela 1 - Análises de clorita em rochas da Mina de Ouro do Igarapé Bahia. Colunas l a 3 gabro granofiríco carbonatizado, 4 a 7 formação ferrifera carbonática,

\begin{tabular}{|c|c|c|c|c|c|c|c|}
\hline $\begin{array}{l}\text { Amostra/ } \\
\text { Análise }\end{array}$ & $\begin{array}{l}1 \\
\text { BAH- } \\
\text { F22- } \\
253-1 \\
\end{array}$ & $\begin{array}{l}2 \\
\text { BAH- } \\
\text { F22. } \\
253.2\end{array}$ & $\begin{array}{l}3 \\
\text { BAH- } \\
\text { F22- } \\
253-3\end{array}$ & $\begin{array}{l}4 \\
\text { BAH- } \\
\text { FI3A- } \\
592 \\
\end{array}$ & $\begin{array}{l}5 \\
\text { BAH- } \\
\text { F13A- } \\
592 \\
\end{array}$ & $\begin{array}{l}6 \\
\text { BAH- } \\
\text { FI3A- } \\
592 \\
\end{array}$ & $\begin{array}{l}7 \\
\text { BAH- } \\
\text { FI3A- } \\
592\end{array}$ \\
\hline $\mathrm{SiO}_{2}$ & 31.71 & 31,54 & 31,06 & 21.43 & 22,16 & 21,73 & 22,40 \\
\hline $\mathrm{TiO}_{2}$ & 0,12 & 0,00 & 0,02 & 0,07 & 0,06 & 0.03 & 0,03 \\
\hline $\mathrm{Al}_{2} \mathrm{O}_{3}$ & $13,0]$ & 13,80 & 13,20 & 19,79 & 21,39 & 20,47 & 20.94 \\
\hline $\mathrm{FeO}$ & 22,70 & 21,67 & 21,31 & 41,40 & 43,09 & 42,36 & 41,92 \\
\hline $\mathrm{MnO}$ & 0,09 & 0,09 & 0.11 & 0,42 & 0,22 & 0,33 & 0,32 \\
\hline $\mathrm{MgO}$ & 19,38 & 19,93 & 20,11 & 2,04 & 1,93 & 2,20 & 2,12 \\
\hline $\mathrm{CaO}$ & 0,11 & 0.10 & 0.18 & 1.34 & 0,35 & 1,23 & 1,07 \\
\hline $\mathrm{Na}_{2} \mathrm{O}$ & 0,03 & 0,01 & 0,00 & 2,04 & 0,04 & 0.05 & 0,08 \\
\hline $\mathrm{K}_{2} \mathrm{O}$ & 0,00 & 0,00 & 0,00 & 0,00 & 0,00 & 0.00 & 0,00 \\
\hline Total & 87,15 & 87.14 & 85.99 & 88,53 & 89,24 & 88,40 & 88,88 \\
\hline $\mathrm{Si}$ & 6591 & 6,317 & 6,511 & 5,026 & 5,096 & 5,068 & 5,159 \\
\hline $\mathrm{Al}^{\mathrm{IV}}$ & 1,409 & 1,483 & 1,489 & 2,974 & 2,904 & 2,932 & 2,841 \\
\hline Soma $\mathbf{T}$ & 8,000 & 8,000 & 8.000 & 8,000 & 8,000 & 8,000 & 8,000 \\
\hline $\mathrm{Al}^{\mathrm{V} / \mathrm{I}}$ & 1,776 & 1,875 & 1,769 & 2,492 & 2,889 & 2,690 & 2,838 \\
\hline $\mathrm{Ti}$ & 0,019 & 0,000 & 0.003 & 0.012 & 0,010 & 0,005 & 0,005 \\
\hline $\mathrm{Fee}^{2}$ & 3,946 & 3,745 & 3.736 & 8,120 & 8,287 & 8,262 & 8.073 \\
\hline Mn & 0,016 & 0,016 & 0,020 & 0,083 & 0,043 & 0,065 & 0,062 \\
\hline $\mathrm{Mg}$ & 6,005 & 6,139 & 6.284 & 0.713 & 0,662 & 0.765 & 0,728 \\
\hline $\mathrm{Ca}$ & 0,024 & 0,022 & 0,040 & 0,337 & 0,086 & 0,307 & 0.264 \\
\hline $\mathrm{Na}$ & 0,012 & 0,004 & 0,000 & 0,928 & 0,018 & 0,023 & 0,036 \\
\hline Cations & 19,798 & 19,801 & 19,852 & $\begin{array}{l}20,685 \\
09\end{array}$ & 19,997 & 20,119 & $\begin{array}{l}20,006 \\
0 \infty\end{array}$ \\
\hline $\begin{array}{l}\mathrm{Fel} \\
\mathrm{Fe}+\mathrm{Mg}\end{array}$ & 0.40 & 0,38 & 0,37 & 0,92 & 0.93 & 0.92 & 0.92 \\
\hline $\begin{array}{l}\mathrm{Mg} / \\
\mathrm{Fe}+\mathrm{Mg}\end{array}$ & 0.60 & 0,62 & 0,63 & 0,08 & 0,07 & 0,08 & 0,08 \\
\hline
\end{tabular}

CARACTERIZAÇÃo QUÍMICA Características químicas do minério primário Visando a caracterização química da mineralização primária da área, foram analisados os elementos $\mathrm{Au}$, As, $\mathrm{Ag}, \mathrm{Cu}, \mathrm{Pb}, \mathrm{Zn}, \mathrm{Rb}, \mathrm{Sr}, \mathrm{Ba}, \mathrm{B}, \mathrm{Mo}$ e Sn em 30 amostras de rocha (Tabela 2).

O ouro ocorre abaixo do limite de detecção, exceto em uma amostra de calcita-clorita-turmalina-xisto que revelou $11 \mathrm{ppm} \mathrm{Au}$.

$\mathrm{Rb}, \mathrm{Sr}, \mathrm{Ba}$, e $\mathrm{B}$, elementos que foram mobilizados durante os processos de alteração, não mostram correlação com nenhum dos mParás, nem entre si. Todavia, o conteúdo de cada um deles reflete perfeitamente a presença ou ausência dos minerais de alteração que os contêm. Assim o Rb, por sua afinidade geoquímica com o K, quando acima de $20 \mathrm{ppm}$ indica a presença de mica na rocha, seja biotita ou mica branca. O Sr, que foi removido das rochas junto com o Ca durante o processo de albitização, encontra-se junto com o Ca na calcita, e valores acima de $20 \mathrm{ppm}$ de $\mathrm{Sr}$ já indicam rochas carbonatizadas. O Ba é um indicador da existência de mica branca, caracterizada por valores superiores a $150 \mathrm{ppm}$, enquanto que valores de B superiores a $200 \mathrm{ppm}$ mostram que a rocha é portadora de turmalina.

As melhores correlações encontradas entre os mParás foram entre $\mathrm{Mo}, \mathrm{Pb}$ e Ag. $\mathrm{Mo}-\mathrm{Pb}=0,913 ; \mathrm{Ag}-\mathrm{Mo}=0,794$ e Ag-Pb $=0,782$. Já o $\mathrm{Cu}$ e $\mathrm{Zn}$ mostraram baixos coeficientes de correlação com os outros mParás. $\mathrm{Cu}-\mathrm{Mo}=0,244 ; \mathrm{Cu}-\mathrm{Ag}=0,392 ; \mathrm{Zn}-\mathrm{Mo}=0,271$ e $\mathrm{Zn}-\mathrm{Ag}=$ 0,413 .

A boa correlação encontrada entre $\mathrm{Mo}, \mathrm{Pb}$ e $\mathrm{Ag}$ associada a presença de molibdenita e fluorita na área, junto com a intensa alteração hidrotermal, sugere influência de fluidos provenientes de rochas graníticas, na concentração destes mParás, o que é suportado pelos estudos de inclusões fluidas. A falta de correlação significativa do $\mathrm{Cu}$ com os outros elementos poderia indicar mais de uma fonte Pará este mPará, ou talvez mais de um estágio de mineralização.

Geoquímica das rochas encaixantes da mineralização ROCHAS SEDIMENTARES Ritmitos No que tange aos óxidos dos elementos maiores (Tabela 3 ), a composição média dos ritmitos estudados é semelhante às médias das rochas sedimentares, tanto arqueanas como proterozóicas, apresentadas por Taylor \& McLennan (1985). A diferença de composição mais marcante, em relação as médias acima referidas, corresponde aos conteúdos mais altos de $\mathrm{FeO}$ e $\mathrm{K}_{2} \mathrm{O}$ e muito mais baixos em $\mathrm{CaO}$ e $\mathrm{Na}_{2} \mathrm{O}$ mostrados pelos ritmitos da Mina do Igarapé Bahia. Eles também mostram grandes semelhanças químicas com as grauvacas arqueanas dos grupos Moodie e Fig Tree, da África do Sul (McLennan 1982), exceto por apresentarem FeO ${ }^{\mathrm{t}}$, $\mathrm{K}_{2} \mathrm{O}, \mathrm{Rb}, \mathrm{La}, \mathrm{Nb}$ e $\mathrm{Cr}$ um pouco mais elevados e $\mathrm{CaO}, \mathrm{Na}_{2} \mathrm{O}$ e $\mathrm{Sr}$ mais baixos. Estas diferenças composicionais com relação a $\mathrm{Ca}, \mathrm{Sr}, \mathrm{K}, \mathrm{Rb}$,

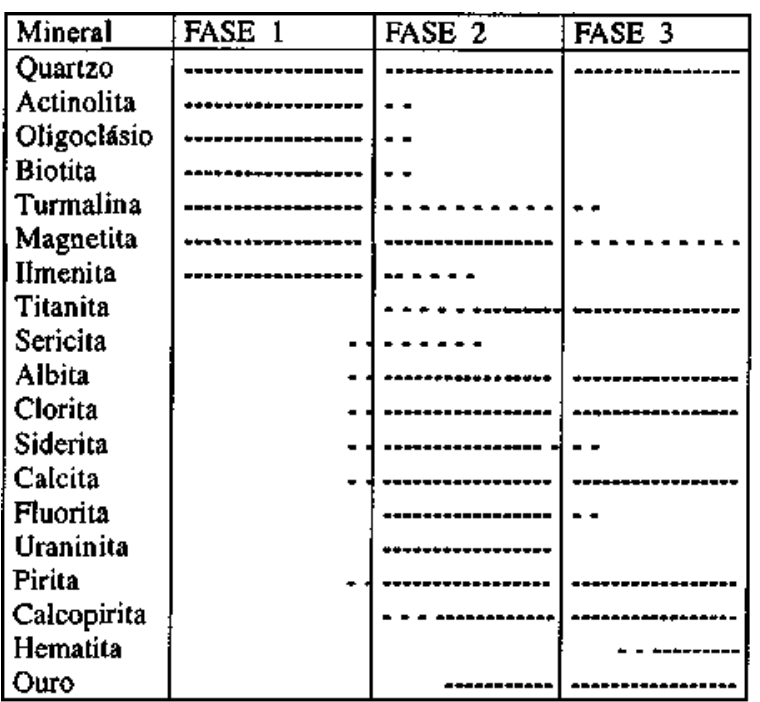

Figura 3 - Sucessão Parágenética dos minerais de minério e ganga, observados na área da mina de Au do Igarapé Bahia. Fase l corresponde à assembléia metamórfica (menos hidratada e de mais alta temperatura). A fase 2 é representada pela Parágênese de alteração hidrotermal dominante na área, formada a uma temperatura de $270^{\circ} \mathrm{C}$ (Lindenmayer \& Laux, em preParáção). A fase 3 compreende a associação mineral de mais baixa temperatura $\left(\sim 170^{\circ} \mathrm{C}\right.$, Lindenmayer \& Laux, em preParáção).

Tabela 2 - Análises químicas de alguns elementos traço, efetuadas em rochas hospedeiras da mineralização da Mina deAudo Igarapé Bahia - (nd) não detectado.

\begin{tabular}{|c|c|c|c|c|c|c|c|c|c|}
\hline 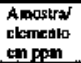 & For-124 & FIII]I] & F11.126 & FII-1+0 & FII-\$BI & $F[1-23]$ & FI1.260 & $F 11: 276$ & FII-J16 \\
\hline $\begin{array}{l}\text { Ba } \\
\mathrm{Bb}\end{array}$ & $\begin{array}{l}3900 \\
89\end{array}$ & $\begin{array}{l}80 \\
10\end{array}$ & 8 & $\begin{array}{l}648 \\
71\end{array}$ & 20 & $\begin{array}{l}10 \\
\text { ind }\end{array}$ & $\begin{array}{l}2566 \\
21\end{array}$ & $\begin{array}{l}610 \\
13\end{array}$ & $\begin{array}{l}19 \\
6\end{array}$ \\
\hline Rb & & $\begin{array}{l}100 \\
11\end{array}$ & & $\begin{array}{l}71 \\
16\end{array}$ & & & & & \\
\hline cu & 2765 & 243 & 1160 & 514 & {$[177$} & 4900 & $17 !$ & 129 & $3 / 49$ \\
\hline Pt & 19 & 99 & 40 & $n$ & 28 & 45 & 31 & 24 & 26 \\
\hline All & ind & nd & nd & nd & nd & nd & nd & nd & at \\
\hline$A_{R}$ & 2 & 2 & 4 & 2 & & 3 & 2 & I & \\
\hline Mdo & 9 & 16 & 16 & 13 & 10 & 22 & 20 & 9 & 29 \\
\hline$A s$ & I & 2 & 6 & 104 & $T$ & & & & 3 \\
\hline $\mathbf{z}_{\mathbf{q}}$ & 29 & 179 & ill & 74 & 自 & 3 & 48 & & \\
\hline & 27 & in & iI & sa & 98 & 31 & 24 & 29 & all \\
\hline
\end{tabular}

\begin{tabular}{|c|c|c|c|c|c|c|c|c|c|}
\hline 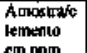 & F1.-31\% & FII. 344 & FII-378 & FI I-j85 & FII & Fll-S:S & FI6-1069 & F[6.II] & $F \mid 6-130$ \\
\hline 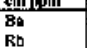 & 24 & $\begin{array}{l}16900 \\
21\end{array}$ & $\frac{71}{10}$ & ed & $\begin{array}{l}670 \\
97\end{array}$ & 8 & $\begin{array}{l}246 \\
25\end{array}$ & 315 & $\begin{array}{l}\text { 3011 } \\
27\end{array}$ \\
\hline sr & & II & 10 & & 94 & & 10 & 10 & \\
\hline & 330 & ins & $25 T$ & ilst & 17 & $47^{9}$ & 2005 & 1242 & 1964 \\
\hline Ph & 117 & 32 & 32 & 32 & 32 & 12 & 24 & 3] & 21 \\
\hline & 11,9 & id & tati & a & ind & nd & nd & nit & 政 \\
\hline A & 5 & 2 & $=$ & 2 & 2 & 2 & 2 & ${ }_{2}$ & I \\
\hline Mo & 118 & 7 & 15 & 12 & 13 & 16 & 12 & 16 & 13 \\
\hline As & 2 & i & 4 & $i$ & 2 & I & 4 & 5 & 2 \\
\hline z. & 145 & 65 & 67 & 79 & 304 & 159 & 39 & 38 & to \\
\hline B & $2 \%$ & 16 & 310 & 96. & $\mathrm{~m}$ & it & 16 & 19 & 37 \\
\hline
\end{tabular}

\begin{tabular}{|c|c|c|c|c|c|c|c|c|c|}
\hline 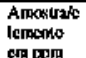 & FI6-153 & F16-150 & Flo 549 & F16-549 & F16-96 & FI6-98,7 & $F \mid 1+130$ & F $16-124$ & F]E-159 \\
\hline 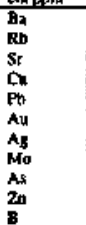 & $\begin{array}{l}190 \\
23 \\
7 \\
82 x \\
23 \\
\text { ad } \\
1 \\
13 \\
20 \\
30 \\
17\end{array}$ & $\begin{array}{l}250 \\
21 \\
8 \\
3833 \\
16 \\
16 \\
2 \\
13 \\
15 \\
25 \\
59\end{array}$ & $\begin{array}{l}4 \\
5 \\
31 \\
41 \\
34 \\
140 \\
2 \\
15 \\
3 \\
151 \\
10\end{array}$ & $\begin{array}{l}284 \\
40 \\
100 \\
1157 \\
37 \\
100 \\
2 \\
12 \\
6 \\
57 . \\
90\end{array}$ & $\begin{array}{l}20 \\
8 \\
5 \\
6200 \\
32 \\
01 \\
3 \\
19 \\
2 \\
61 \\
62\end{array}$ & $\begin{array}{l}70 \\
16 \\
10 \\
40 \\
45 \\
34 \\
2 \\
2 \\
21 \\
77 \\
64 \\
27\end{array}$ & $\begin{array}{l}249 \\
17 \\
11 \\
419 \\
34 \\
104 \\
2 \\
14 \\
15 \\
46 \\
98\end{array}$ & $\begin{array}{l}353 \\
30 \\
9 \\
650 \\
23 \\
70 \\
1 \\
22 \\
2 \\
70 \\
79\end{array}$ & 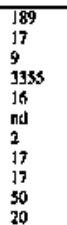 \\
\hline
\end{tabular}

$\mathrm{Na}$ e Fe são facilmente explicáveis pela mobilidade destes elementos, já vislumbrada a partir das transformações mineralógicas que ocorreram em todas as rochas da área, em resposta ao processo de alteração hidrotermal. A presença de conteúdos mais eleva-dos em $\mathrm{La}$ e $\mathrm{Nb}$ pode ser atribuída à influência de fluidos gra- níticos nos processos de alteração, à semelhança do que ocorre no depósito de Cu do Salobo (Lindemayer 1990). Os valores mais altos Cr podem ser devidos à diferença de fonte existente entre os ritmitos estudados e os anteriormente referidos.

Os ritmitos são provenientes principalmente de basaltos toleiíticos, como pode ser observado no diagrama $\mathrm{Cr}-\mathrm{TiO}_{2}$ (Fig. 4) onde eles se 


\begin{tabular}{|c|c|c|c|c|c|c|c|c|c|c|c|c|c|c|c|c|c|c|c|c|c|c|c|}
\hline $\begin{array}{l}\text { Amostrol } \\
\text { etempedo }\end{array}$ & $\begin{array}{c}1 \\
\text { R-10-124 }\end{array}$ & $\begin{array}{c}2 \\
P=10-125\end{array}$ & $\begin{array}{c}3 \\
\text { P-10-183 }\end{array}$ & F.11-161 & $\begin{array}{c}5 \\
F-11-197\end{array}$ & $\begin{array}{c}6 \\
\mathrm{P}-11.204\end{array}$ & $\begin{array}{c}7 \\
\text { P. } 11-301\end{array}$ & $\begin{array}{c}8 \\
\text { P-13A-S72 }\end{array}$ & $\begin{array}{c}9 \\
\text { P-16-298 }\end{array}$ & $\begin{array}{c}10 \\
R_{1}^{16.304}\end{array}$ & $\begin{array}{c}11 \\
\text { F-16-308 }\end{array}$ & $\begin{array}{c}12 \\
\text { P-16-312 }\end{array}$ & $\begin{array}{c}13 \\
p_{1} 16-108\end{array}$ & $\begin{array}{c}14 \\
\text { P.16-64 }\end{array}$ & $\begin{array}{c}15 \\
\text { P-16-69 }\end{array}$ & $\begin{array}{c}16 \\
\text { P-16-84 }\end{array}$ & $\begin{array}{c}17 \\
1.222 .248\end{array}$ & $\begin{array}{c}18 \\
\text { R-22-253 }\end{array}$ & $\begin{array}{c}19 \\
\text { F } 22.253\end{array}$ & $\begin{array}{c}20 \\
\mathrm{~F}-24-412,5\end{array}$ & $\begin{array}{c}21 \\
\mathbf{P} \cdot 24 \cdot 413,2\end{array}$ & $\begin{array}{c}22 \\
\text { P.2 } 24 \cdot 413,3\end{array}$ & $\begin{array}{c}23 \\
\text { P.24-413,8 }\end{array}$ \\
\hline $\mathrm{SiO}_{2}$ & 49,20 & 48,30 & 50,00 & 58,80 & 58,80 & 60.60 & 53,40 & 4.90 & 56,80 & 55,30 & 55.60 & 57,10 & $59, A 0$ & 58,30 & 58,70 & 59,90 & 20.40 & 22,20 & 27.20 & 50,60 & 50,30 & 50,60 & 50,10 \\
\hline $\mathrm{TiO}_{4}$ & 1,30 & 1.33 & 1,36 & 0,70 & 0,70 & 0,58 & 0,62 & 0,01 & 1,80 & 1,70 & 1,70 & 1,60 & 0.73 & 0,58 & 0.66 & 0,57 & 0.21 & 0,28 & 0.35 & 0.95 & 0,90 & 0.91 & 0,97 \\
\hline $\mathrm{Al}_{3} \mathrm{O}_{1}$ & 13,40 & 13,60 & 13,60 & 17,00 & 19,20 & $17 A 0$ & 14,50 & 0,01 & 12.20 & 12,40 & 12,40 & 11,80 & 15,00 & 16,10 & 17,90 & 15,50 & 4,10 & 4,90 & 3,50 & 15,70 & 14,40 & 14.80 & 14,30 \\
\hline $\mathrm{Pe}_{3} \mathrm{O}_{2}$ & 17,40 & 19,90 & 16,70 & 6.70 & 4,90 & 5,90 & 11,90 & 71.90 & 4,0 & 5,00 & 4,30 & 4.70 & 7.50 & 5,90 & 5,90 & 6,10 & 2.20 & 2.40 & 2,60 & 1,80 & 3.50 & 330 & 3.40 \\
\hline $\mathrm{FeO}$ & 0,01 & 0,01 & 0,01 & 7,00 & 4,30 & 450 & 9,60 & 11,20 & 9,90 & 9,90 & 10,50 & 10,30 & 7,80 & 8,40 & 3,90 & 7,70 & 4.90 & 7,60 & 8,00 & 9,10 & 7,80 & 8.0 & 8.40 \\
\hline $\mathrm{MnO}$ & 0,32 & 0,30 & 0,35 & 0,09 & 0,05 & 0,07 & 0,14 & 0.19 & 0,07 & 0,11 & 0,10 & 0,10 & 0,07 & 0,09 & 0,06 & 0,08 & 0,45 & 1,30 & 1,10 & 0.19 & 0,19 & 0,20 & 0.20 \\
\hline MgO & 5,13 & 5,37 & 3,44 & 1,40 & 2,10 & 1.80 & 2.60 & 0.01 & 6,70 & 6,90 & 6.60 & 6,40 & 1.90 & 2,50 & 1,90 & 2.30 & 9,80 & 10.70 & 10,90 & 6.50 & 7,40 & 7.10 & 7,30 \\
\hline $\mathrm{CaO}$ & 7.74 & 6,05 & 7,32 & 0,15 & 0,13 & 0.12 & 0,17 & 7,30 & 0,76 & 0,82 & 0,92 & 0,72 & 0,17 & 0.09 & 0,07 & 0,10 & 29,40 & 22,60 & 20,00 & 11,10 & 11,40 & 11.20 & 10,40 \\
\hline $\mathrm{N}_{2}, \mathrm{O}$ & 2,35 & 1,83 & 2,65 & 0,08 & 3,12 & 0.12 & 0,04 & 0,01 & 2,10 & 2200 & 2,20 & 1,70 & 0,07 & 0,08 & 0,11 & 0,08 & 0,03 & 0,03 & 0,02 & 2,10 & 2,10 & 2,10 & 1,90 \\
\hline $\mathrm{K}_{2} \mathrm{O}$ & 1,09 & 1,77 & 0,85 & 3,60 & 4.90 & 4,10 & 1,50 & 0,01 & 0,03 & 0.02 & 0,02 & 0,03 & 2,80 & 3,00 & 4,30 & 2,90 & $\mathbf{n d}$ & 0,01 & 0.01 & 0,45 & 0,31 & 0,32 & 0,95 \\
\hline $\mathbf{P}_{2} \mathbf{O}_{3}$ & 0,13 & 0.12 & 0,15 & 0.09 & 0,09 & 0,07 & 0,11 & nd & 0.45 & 0,49 & 0,50 & 0.46 & 0,11 & 0,05 & 0.05 & 0,06 & 0,05 & 0,07 & 0,16 & 0,07 & 0,07 & 0,07 & 0,06 \\
\hline $\mathbf{P F}$ & 1,85 & 2,23 & 1,70 & 3,61 & 4,25 & 3,97 & 4,19 & 3,07 & 3,93 & 3,95 & 3,85 & 3,82 & 3,37 & 3.82 & 3,63 & 3,58 & 27,18 & 26.83 & 23,05 & 0.26 & 0,63 & 0,31 & 0,96 \\
\hline Tots & 99.91 & 100,30 & 100,32 & 99,14 & 99,34 & 99,33 & 98,89 & 98,72 & 98,84 & 98.89 & 98,80 & 98,83 & 99,02 & 99,02 & 99,30 & 98,99 & 99,34 & 99,07 & 99.04 & 98,93 & 99,12 & 99,01 & 99.06 \\
\hline $\mathbf{B a}$ & 140 & 290 & 220 & 495 & 653 & 530 & 455 & ad & ad & od & Dd & nd & 490 & 393 & 515 & 515 & 34 & 12 & 16 & 13 & 35 & nd & 34 \\
\hline $\mathbf{R b}$ & ndd & 50 & 30 & 91 & 133 & 110 & 30 & 6 & 6 & 6 & 6 & 7 & S1 & 67 & 100 & 65 & 6 & od & 5 & 17 & 15 & 13 & 37 \\
\hline$S_{\boldsymbol{s}}$ & 70 & 50 & 120 & 15 & 18 & 13 & nd & 5 & 16 & 11 & 13 & 11 & 11 & 10 & 16 & 11 & 43 & 29 & 26 & 88 & 74 & 82 & 69 \\
\hline Nb & 30 & 20 & 20 & 10 & 13 & 125 & 10 & 6 & 14 & 15 & 14 & 15 & 11 & 8 & 12 & 10 & 15 & 6 & nd & 6 & nd & 9 & 7 \\
\hline$z_{r}$ & 70 & 70 & 130 & 148 & 137 & 15 & 107 & 5 & 191 & 201 & 202 & 199 & 116 & 113 & 140 & 116 & 199 & 48 & 53 & 55 & 52 & 55 & 47 \\
\hline $\mathbf{Y}$ & 20 & 20 & 40 & 17 & 18 & 17 & 6 & nd & 23 & 20 & 24 & 16 & 7 & 11 & 16 & 7 & 13 & 28 & 76 & 19 & 18 & 14 & 16 \\
\hline In & bed & nd & bd & 14 & 13 & 17 & 10 & ad & 14 & 14 & 11 & $B$ & 11 & 9 & 12 & 12 & nd & nd & nd & nd & ad & 6 & nd \\
\hline $\mathbf{U}$ & 10 & 10 & 10 & 15 & ind & od & 17 & 14 & 19 & 14 & 17 & 17 & 16 & 13 & 10 & It & 17 & 13 & 17 & 10 & 13 & 16 & 10 \\
\hline$\alpha$ & 170 & 170 & 170 & 218 & 246 & 218 & 225 & 130 & 34 & 54 & 54 & $\$ 4$ & 225 & 205 & 218 & 205 & 27 & 68 & 82 & 205 & 232 & 212 & 239 \\
\hline $\mathbf{N i}$ & 60 & 70 & 60 & 78 & 62 & 70 & 39 & 8 & B & 8 & 8 & 8 & 70 & 86 & 86 & 94 & 8 & 39 & 62 & 94 & 110 & 102 & 110 \\
\hline $\mathbf{F}$ & ma & na & na & 380 & 470 & 490 & 400 & 160 & 670 & 690 & 720 & 620 & 400 & 500 & 640 & 580 & 990 & 1100 & 1100 & 300 & 310 & 260 & 320 \\
\hline $\mathbf{a}$ & pa & na & na & 210 & 130 & 120 & 350 & 70 & 220 & 220 & 230 & 230 & 240 & 200 & 140 & 220 & 110 & 170 & 210 & 590 & 370 & 360 & 240 \\
\hline La & nas & Da & an & 45,33 & 22,07 & 22,45 & 33.20 & 2,03 & 20.89 & 19,55 & 14,52 & 24,87 & 40.28 & $2, A 2$ & 19.72 & 2,33 & 10,55 & 34,400 & 94,01 & 3,69 & 3.71 & 4,0 & 4,20 \\
\hline Co & $\mathrm{ma}$ & ma & na & 86,72 & 47,28 & 56,42 & 56,42 & 3,239 & 46.63 & 44,55 & 33,16 & 56,23 & 68.63 & 4,315 & 42,320 & 4,091 & 20,180 & 64,310 & 179,100 & 10,46 & 9,892 & 10,48 & 10,56 \\
\hline Nd & Da & Da & on & 34,48 & 18,60 & 17,34 & 17,49 & 0,79 & 23,89 & 22,120 & 16.490 & 24.28 & 20,27 & 1,575 & 16,490 & 1,529 & 7,800 & 23,810 & 67.250 & 6,25 & 6.319 & 6,111 & 6,428 \\
\hline Son & wa & $m$ & an & 5.281 & 2,811 & 2,696 & 2,443 & 0,100 & 4,56 & 4.358 & 3,194 & 4,574 & 3,132 & 0.245 & 2,370 & 0310 & 1,543 & 4,475 & 12530 & 1.942 & 1.741 & 1,607 & 1,744 \\
\hline En & na & m & 吸 & 0.988 & 0.523 & 0.518 & 0,83 & 0,171 & 0,863 & 0.828 & 0.714 & 0.791 & 1,479 & 0.171 & 0.499 & 0,183 & 1,543 & 1,965 & 3.164 & 0.628 & 0,550 & 0.516 & 0.572 \\
\hline $\mathbf{G d}$ & na & na & ma & 2,922 & 1,794 & 1,553 & 1,52 & 0,093 & 3.668 & 3.755 & 3,036 & $\mathbf{3 , 1 7 0}$ & 1.903 & 0.361 & 1,404 & 0,430 & 1,453 & 3.521 & 8.939 & 1,873 & 1,763 & 1,644 & 1.799 \\
\hline Dy & wa & na & ba & 2,342 & 1,979 & 1,571 & 1,444 & 0,095 & 3,944 & 4.732 & 4,134 & 2,911 & 1,849 & 0,590 & 1,753 & 0,660 & 1,522 & 2.512 & 6.428 & 2,117 & 2,111 & 1,868 & 2,304 \\
\hline Ho & $\mathbf{b a}$ & be & na & 0.461 & $0,415$. & 0,394 & 0,297 & 0,018 & 0,781 & 0.945 & 0.792 & 0.604 & 0,380 & 0.139 & 0.361 & 0,159 & 0,309 & 0,465 & 1.168 & 0.416 & 0,414 & 0,371 & 0,473 \\
\hline Ex & wa & na & pa & 1,201 & 1,214 & 0,996 & 0.844 & 0,050 & 2,063 & 2537 & 1,959 & 1.733 & 1,073 & 0.393 & 1,025 & 0,472 & 0,780 & 1,064 & 2.533 & 1,080 & 1.070 & 0,987 & 1,331 \\
\hline Yb & wa & ba & ne & 1,088 & 1,221 & 0,977 & 0,833 & 0,046 & 1,653 & 2,338 & 1,448 & 1,442 & 1,041 & 0,505 & 0,928 & 0,558 & 0,561 & 0,676 & 1.466 & 0.851 & 0,865 & 0,819 & 1.125 \\
\hline Lu & wa & $\mathbf{n a}$ & na & 0,152 & 0,163 & 0,144 & 0,129 & 0,010 & 0,208 & 0,287 & 0,171 & 0,210 & 0,138 & 0,068 & 0,115 & 0,076 & 0,084 & 0,098 & 0,186 & 0.109 & 0,121 & 0,116 & 0,156 \\
\hline
\end{tabular}

Tabela 3 - Análises químicas de elementos maiores, traços e ETR em rochas encaixantès da mineralização da Mina de Au do Igarapé Bahia, (na = não analisado, nd = não detectado).Colunas

1 e 2 - metabasalto, 3 - gabro granofírico, 4, a 7 ritmito, 8 formação ferrifera, 9 a 12 gabro granofírico, 13 a 16 rítmito, 17 a 19 xisto carbonático, 20 a 23 diabásio. 


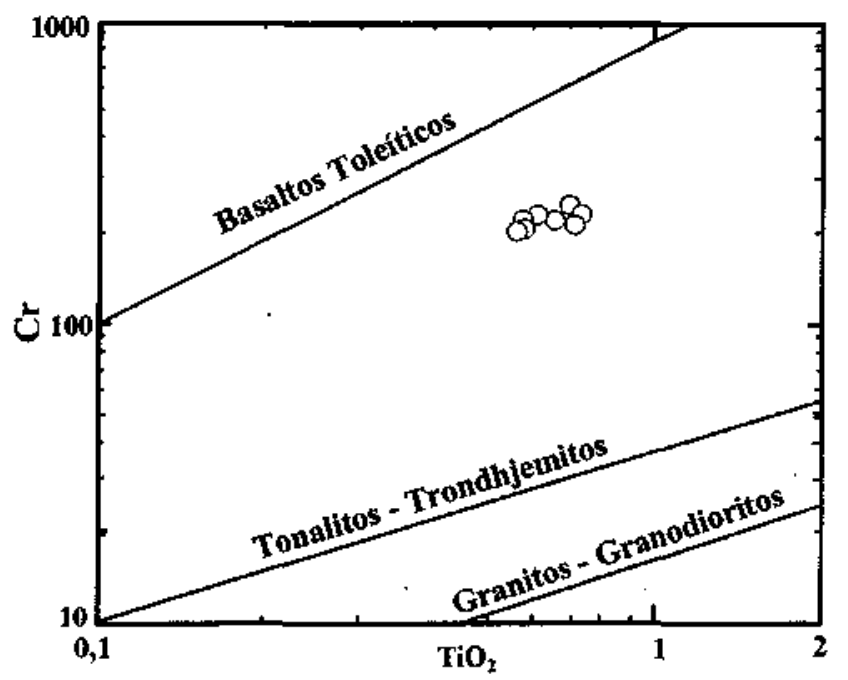

Figura 4 - Diagrama mostrando proveniencia principalmente de basaltos toleiíticosPará os ritmitos. As curvas correspondem às razões $\mathrm{Cr} / \mathrm{TiOi}$ características de basaltos toleiíticos, tonalitos-trondhjemitos e granitos-granodioritos de Laskowski \& Krõner (1985).

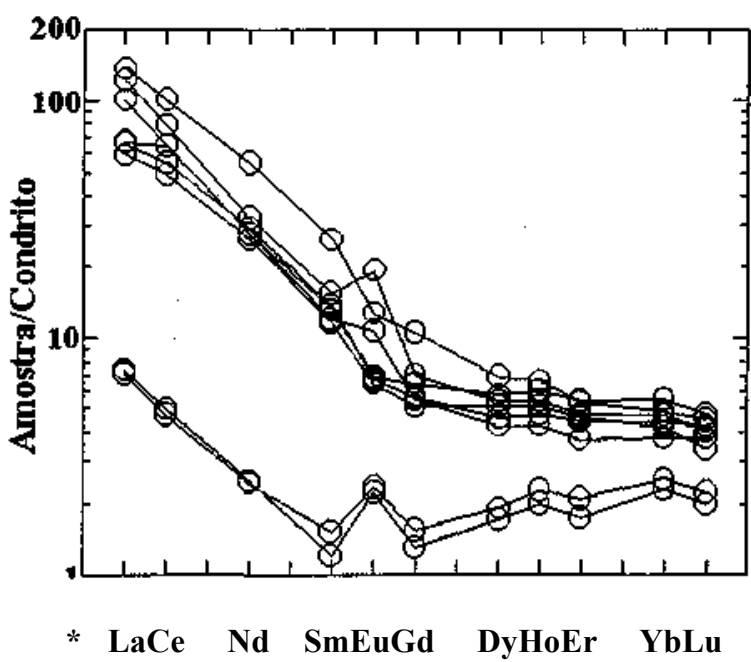

Figura 5 - Padrões de ETR dos ritmitos normalizados pelo condrito de Nakamura (1974).

situam próximos da curva representativa da razão $\mathrm{Cr} / \mathrm{TiO}_{2}$ dos basaltos toleí́ticos de Laskowski \& Krõner (1985).

Os ritmitos possuem Th (14,37 ppm) e U (13,66 ppm) muito elevado em relação à média dos sedimentos arqueanos $(10$ e $2,5 \mathrm{ppm}$, respectivamente), mas a razão $\mathrm{Th} / \mathrm{U}$ é baixa $(1,05)$ se comParáda as rochas sedimentares arqueanas (Condie 1993), onde esta razão varia entre 3,5 e 4,5. Isto se deve ao fato dos sedimentos da área estudada serem muito ricos em $\mathrm{U}$.

Com relação aos ETR, os ritmitos mostram padrões tipicamente arqueanos com 2ETR $=86,62-180,96 \mathrm{ppm} \mathrm{e} \mathrm{Eu}_{\mathrm{n}} / \mathrm{Eu}^{*}=0,667-1,719$, com exceção de duas amostras de ritmitos brechados que apresentam valores muito baixos de elementos terras raras (Fig. 5). Apesar dos padrões normalizados pelo condrito serem compatíveis com os padrões arqueanos (Condie 1993), eles se encontram mais enriquecidos em elementos terras leves (ZETRL/SETRP $=13,27-21,03)$ que os seus similares arqueanos $2 \mathrm{ETRL} / \mathrm{ZETRP}<10$, ou mesmo mais ricos do que a média dos sedimentos finos proterozóicos, mostrada por Taylor \& McLennan (1985).

Este enriquecimento em ETRL, U, K, Rb, em desacordo com a razão $\mathrm{Cr} / \mathrm{TiO}_{2}$, aponta Pará a presença de uma fonte crustal continental importante Pará os fluidos responsáveis pela alteração hidrotermal havida na área. Enriquecimento semelhante ocorre na área do depósito de $\mathrm{Cu}-\mathrm{Au}$ do Salobo, relacionado à intrusão do granito anorogênico jovem (Lindenmayer 1990).
Formação Ferrifera A formação ferrífera é constituída basicamente por três componentes: $\mathrm{FeO}(75,91 \%), \mathrm{CaO}(7,3 \%)$ e $\mathrm{SiO}_{2}(4,9 \%)$, em concordância com a mineralogia observada.

Ela mostra um padrão de ETR semelhante a asa de pássaro "birds wing", tal como a maioria das formações ferríferas arqueanas (Fig. 6). Seu pequeno fracionamento em ETRP $\left(\mathrm{Gd} / \mathrm{Lu}_{\mathrm{n}}=1,154\right)$, anomalia positiva de $\mathrm{Eu}\left(\mathrm{Eu} / \mathrm{Eu}^{*}=5,337\right)$ e conteúdo total de ETR $(\Sigma \mathrm{ETR}=6,643$ ppm) também é semelhante ao das formações ferríferas de mesma idade, encontrando-se dentro do intervalo de variação apresentado pelas formações ferríferas da Formação Carajás ( $\Sigma$ ETR $=6,12-13,01$ ppm, Lindenmayer \& Laux, em preparáção). Todavia, ela apresenta um fracionamento expressivo em ETRL $\left(\mathrm{La}_{\mathrm{n}} / \mathrm{Sm}_{\mathrm{n}}=12,787\right)$. Seu conteúdo de U (14 ppm) também é mais elevado do que aquele característico das formações ferríferas arqueanas, o que leva a sugerir que uma fonte crustal continental também teve um papel importante na formação ou transformação destas rochas, embora elas não sejam enriquecidas em elementos terras raras totais. ROCHAS MÁFICAS O magmatismo basáltico da área $\mathrm{j}$ á foi exaustivamente estudado por Sachs (1993). Neste trabalho são abordados apenas os aspectos das rochas máficas, pertinentes à caracterização do perfil estudado e à mineralização sulfetada associada.

Tanto o sill granofírico como o dique de diabásio são provenientes da cristalização de um magma basáltico toleiítico (Fig. 7).

O dique de diabásio tem concentrações de ETR compatíveis com basaltos arqueanos $(\Sigma \mathrm{ETR}=28,519-30,692 \mathrm{ppm})$, ou seja, inferiores a 10 vezes o condrito. Os padrões normalizados pelo condrito exibem uma curva com um peque-no fracionamento dos elementos terras raras pesados $\left(\mathrm{La}_{\mathrm{n}} / \mathrm{Lu}_{\mathrm{n}}=3,187-3,581\right),\left(\mathrm{La}_{\mathrm{n}} / \mathrm{Sm}_{\mathrm{n}}=1.197-1.568\right) \mathrm{e}$ praticamente sem anomalias de $\mathrm{Eu}\left(\mathrm{Eu}_{\mathrm{n}} / \mathrm{Eu}^{*}=0,951-0,994\right)$ (Fig. 8).

Os metabasaltos mostram razões $\mathrm{Ti} / \mathrm{Zr}$ e $\mathrm{Zr} / \mathrm{Y}$ dentro do intervalo de variação dos toleí́tos arqueanos (Condie 1981), enquanto que no gabro granofírico estas razões apresentam valores que se aproximam dos basaltos de rift modernos. Os metabasaltos, em comParáção com os basaltos toleíticos arqueanos, mostram-se mais ricos em Fe e $\mathrm{K}$ e mais pobres em $\mathrm{Mg}, \mathrm{Ca}, \mathrm{Sr}, \mathrm{Cr}$ e $\mathrm{Ba}$. O gabro granofírico apresenta maiores conteúdos de Fe e menores de $\mathrm{Ca}, \mathrm{Na}, \mathrm{K}, \mathrm{Sr}, \mathrm{Rb}$ e Ba, em comParáção aos mesmos basaltos. Estas variações concordam com as substituições minerais devidas a alteração hidrotermal, descritas anteriormente.

O gabro granofírico alterado mostra um padrão de ETR normalizado pelo condrito, muito semelhante aos dos basaltos do Grupo Grão Pará (Meirelles \& Dardenne 1991). Estas rochas exibem um conteúdo total de terras raras correspondente a 20-30 vezes o condrito $(Z E T R=$ $81,07-120,81)$, apresentando um enriquecimento em terras raras leves $(\Sigma \mathrm{ETRL}=67,364-109,954 \mathrm{ppm})$ e razões $\Sigma$ ETRL $/ \Sigma \mathrm{ETRP}=5,83-$ 10,918 (Fig. 9). Seus padrões normalizados possuem anomalias negativas de $\mathrm{Eu}\left(\mathrm{Eu}_{\mathrm{n}} / \mathrm{Eu}^{*}=0,603-0,691\right)$, que, devido ao estágio avançado de alteração, indicam possivelmente remoção de Eu, junto com o Ca do plagioclásio, concomitante ao processo de albitização.

CALCITA-CLORITA-TURMALINA-XISTO Os calcita-clorita-turmalina-xistos são rochas fortemente foliadas, constituídas predominantemente por $\mathrm{CaO}, \mathrm{SiO}_{2}, \mathrm{MgO}, \mathrm{FeO}$ e $\mathrm{Al}_{2} \mathrm{O}_{3}$ Com relação às rochas máficas que as encaixam, e das quais são provenientes por processos de alteração, elas são enriquecidas em F (300-1100 ppm), Sr (26-88 ppm) e elementos terras raras (2ETR 46,325 -376,794).

Os padrões normalizados pelo condrito correspondem a curvas muito inclinadas $\left(\mathrm{La}_{\mathrm{n}} / \mathrm{Lu}_{\mathrm{n}}=13,037-52,465\right)$, com enriquecimento pronunciado em ETRL $\left(\mathrm{La}_{n} / \mathrm{Sm}_{n}=4,305-4,840\right)$ e anomalias de Eu variando de positivas $\left(\mathrm{Eu}_{\mathrm{n}} / \mathrm{Eu}^{*}=3,105\right)$ a praticamente inexistentes $\left(\mathrm{Eu}_{\mathrm{n}} / \mathrm{Eu}^{*}=0,872\right)$ (Fig. 10).

Estes dados sugerem fortemente que soluções quentes e ricas em $\mathrm{CO}_{2}$ tenham mobilizado os elementos terras raras, junto com o $\mathrm{Ca}, \mathrm{Si}$, $\mathrm{Na}$ e K, na área.

BALANÇO GEOQUíMICO DE MASSA A mobilidade dos elementos acima referidos foi quantificada através de cálculos químicos de balanço de massa. Pará isto foi utilizado o gabro granofírico, a única rocha onde foram identificadas com segurança duas assembléias minerais distintas: uma metamórfica e outra hidrotermal. Foi considerada como rocha mãe a amostra F-10-183 composta por hornblendaactinolita e oligoclásio, representante da assembléia metamórfica, menos hidratada e de mais alta temperatura, encontrada exclusivamente nesta amostra. As rochas filhas (F-16-304, F-16-312, F-16308 e F-16-298) compostas por clorita, quartzo e albita, correspondem a assembléia nitidamente hidrotermal, formada no intervalo de temperatura compreendido entre 270 e $170^{\circ} \mathrm{C}$ (Lindenmayer \& Laux, em 


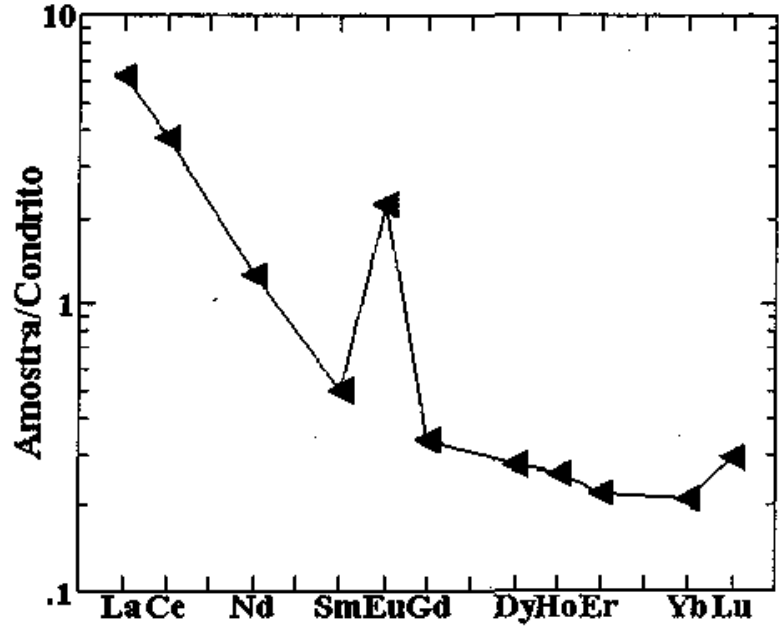

Figura 6 - Padrão de ETR da formação ferrífera óxido-carbonato, normalizado pelo condrito de Nakamura (1974). Note o /racionamento pronunciado dos ETRL.

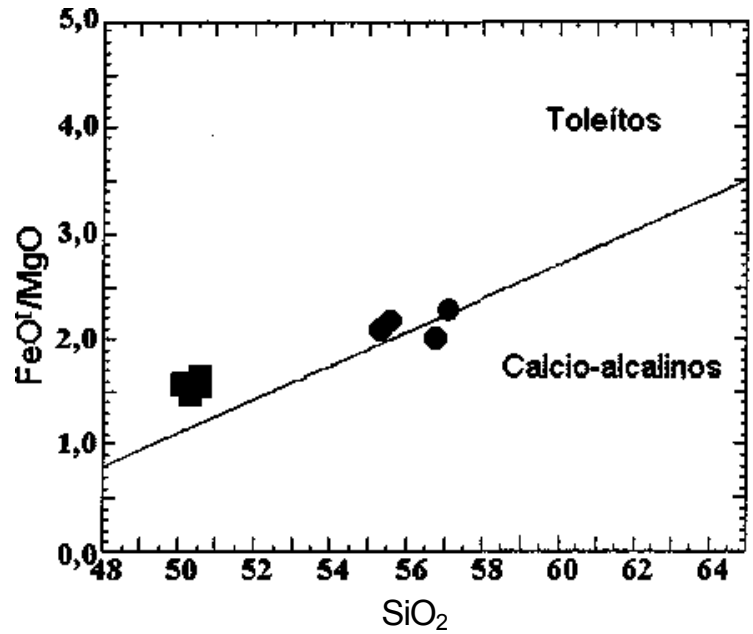

Figura 7 - Diabásio (quadrados) e gabro granofirico (círculos cheios), representados no campo dos basaltos toleiiticos do diagrama de Miyashiro (1974). O ganho de $\mathrm{Mg}$, mais pronunciado do que o de Fe, devido à alteração, é responsável pelo deslocamento das duas amostras mais alteradas do granófiro, em direção ao campo dos basaltos cálcio-alcalinos.

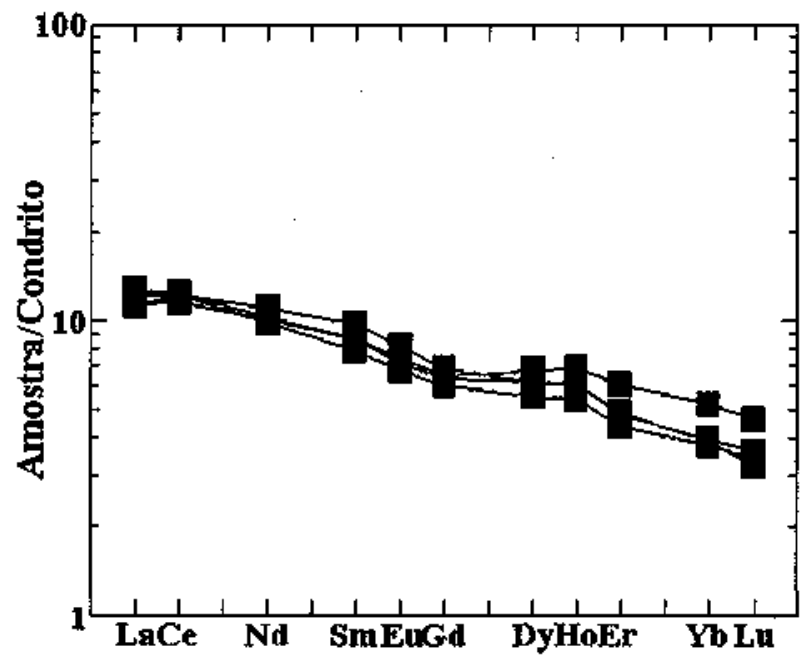

Figura 8 - Padrão de ETR, do diabásío que pós data a mineralização de Cu-Au, normalizado pelo condrito de Nakamura (1974).

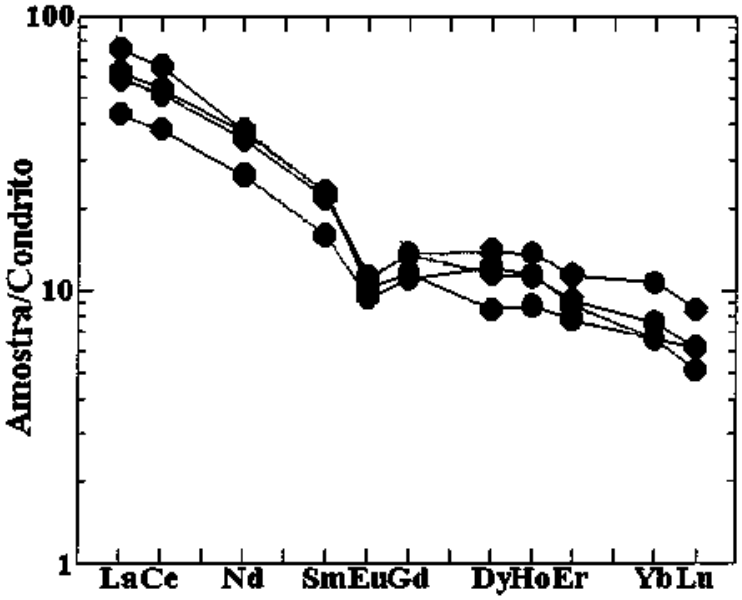

Figura 9 - Padrões de ETR do gabro granofirico, normalizados pelo condrito de Nakamura (1974).

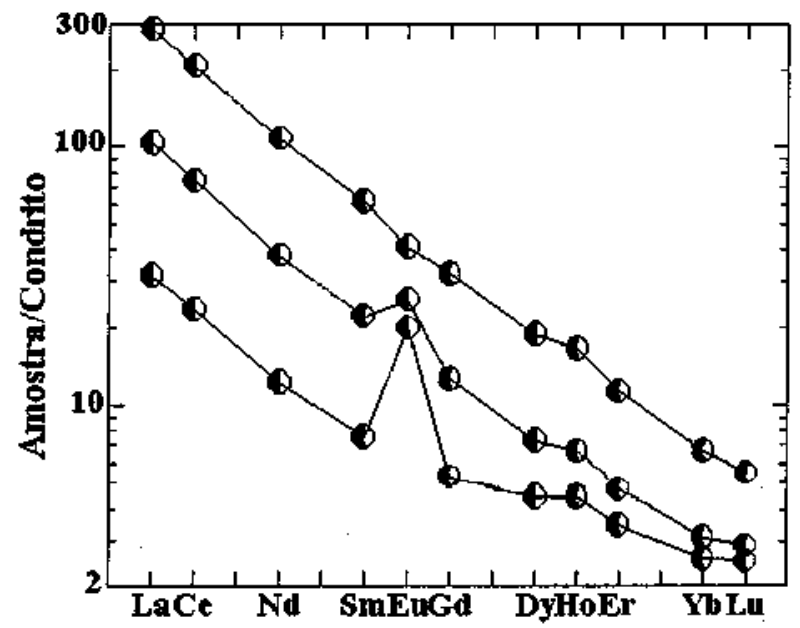

Figura 10 - Padrões de ETR do calcita-clorita-turmalina-xisto, normalizados pelo condrito de Nakamura (1974).

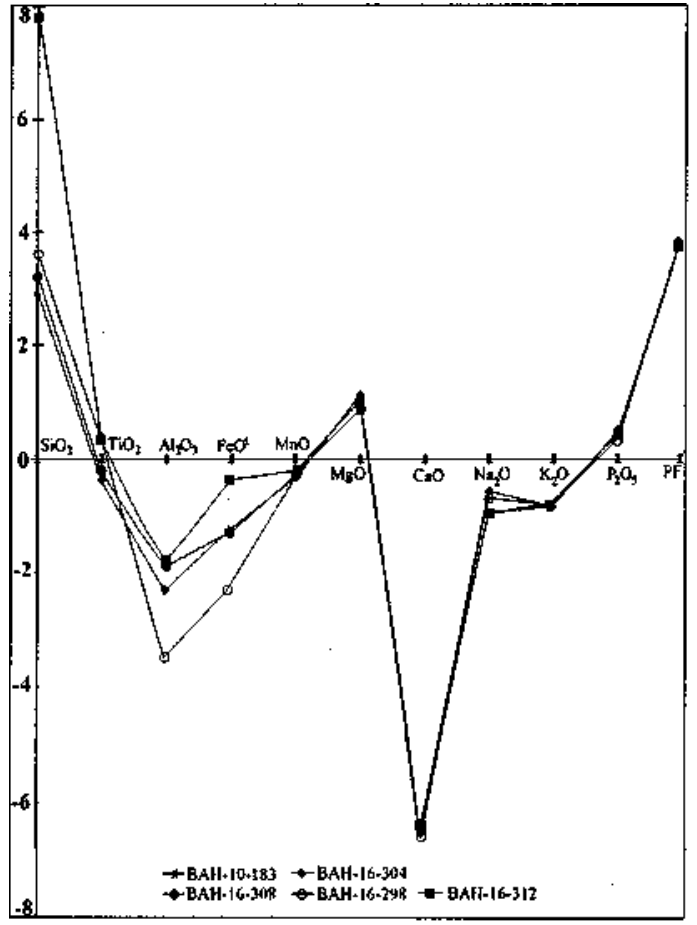

Figura 11 - Diagrama representando as perdas e ganhos ocorridas no granófiro, devido a alteração hidrotermal. 
Tabela 4 - Perdas e ganhos (P-G) das amostras filhas do gabro granofirico cloritizado e hidrotermalmente alterado (BAH-6-304/312/308/298), calculados em relação à rocha mãe, correspondente ao gabro granofirico anfibolítico, metamorfizado(Amostra BAH-10-183). Este último, coletado imediatamente a norte da seção LT - 00, aqui estudada.

\begin{tabular}{|c|c|c|c|c|c|c|c|c|c|}
\hline Amostra & $\mathrm{BAH}-10-183$ & $\mathrm{BAH}-16-304$ & $16-304-\mathrm{P}-\mathrm{G}$ & BAH-16.312 & $16 \cdot 312-P \cdot G$ & BAH-16.308 & $16-308-P-\bar{G}$ & BAH-16-298 & $16-298-P \cdot G$ \\
\hline $\mathrm{SiO}_{2} \%$ & 50.00 & 55.30 & +2.88 & 57.10 & +7.65 & 55.60 & +3.15 & 56.80 & +3.55 \\
\hline $\mathrm{TiO}_{2}$ & 1.36 & 1.70 & -0.40 & 1.60 & +0.25 & 1.70 & -0.26 & 1.80 & +0.33 \\
\hline $\mathrm{Al}_{2} \mathrm{O}_{3}$ & 13.80 & 12.40 & -2.32 & 11.80 & -1.88 & 12.40 & .1 .94 & 12.20 & -3.52 \\
\hline FeOt & 15.03 & 14.40 & -1.25 & 14.53 & -0.36 & 14.37 & -1.29 & 13.50 & -2.30 \\
\hline MnO & 0.35 . & .0 .11 & -0.31 & 0.10 & -0.25 & 0.10 & -0.25 & 0.07 & -0.28 \\
\hline $\mathrm{MgO}$ & 5.44 & 6.90 & +1.16 & 6.40 & +1.02 & 6.60 & +0.87 & 6.70 & +0.87 \\
\hline $\mathrm{CaO}$ & 6.32 & 0.82 & -6.53 & 0.72 & -6.39 & 0.92 & -6.44 & 0.76 & -6.60 \\
\hline $\mathrm{Na}_{2} \mathrm{O}$ & 2.65 & 2.20 & -0.54 & 1.70 & -0.93 & 2.20 & -0.54 & 2.10 & -0.67 \\
\hline $\mathrm{K}_{2} \mathrm{O}$ & 0.85 & 0.02 & -0.83 & 0.03 & -0.82 & 0.02 & -0.83 & 0.03 & -0.82 \\
\hline $\mathrm{P}_{2} \mathrm{O}_{5}$ & 0.15 & 0.49 & +0.32 & 0.46 & +0.31 & 0.50 & +0.33 & 0.45 & +0.27 \\
\hline $\mathrm{PF}$ & 1.70 & 3.95 & & 3.82 & & 3.85 & & 3.93 & \\
\hline Total & 100.32 & 98.89 & & 98.83 & & 98.80 & & 98.84 & \\
\hline $\mathrm{Cr} \mathrm{ppm}$ & 170 & 54 & -118.35 & 54 & -115.47 & 54 & -118.37 & 54 & -119.08 \\
\hline $\mathrm{Ni}$ & 50 & 8 & -42.35 & 8 & -41.92 & 8 & -42.35 & 8 & -42.45 \\
\hline $\mathrm{Ba}$ & 220 & $<10$ & & $<10$ & & $<10$ & & $<10$ & \\
\hline $\mathrm{U}$ & 10 & 20 & +9.13 & 18 & +8.17 & 17 & +6.25 & 19 & +7.91 \\
\hline$R b$ & 30 & 6 & -24.26 & 7 & -22.93 & 6 & -24.26 & 6 & -24.34 \\
\hline $\mathrm{Sr}$ & 120 & 11 & .109 .47 & 11 & .108 .89 & 13 & .107 .57 & 16 & -104.91 \\
\hline $\mathrm{Y}$ & 40 & 20 & -20.87 & 16 & -23.84 & 24 & -17.05 & 23 & -18.31 \\
\hline $\mathrm{Zr}$ & 130 & 201 & +62.23 & 199 & +70.93 & 202 & +63.13 & 191 & +50.09 \\
\hline Dens. & 2.9992 & 2.8475 & & 2.8268 & & 2.8575 & & 2.8350 & \\
\hline Kv & & 1.00735 & & 1.0713 & & 1.0035 & & 0.9975 & \\
\hline
\end{tabular}

preParáção) . Assim sendo, esta quantificação de perdas e ganhos reflete apenas o estágio de alteração responsável pela transformação da assembléia metamórfíca na assembléia de alteração hidrotermal (Fig. 11) (Tabela 4).

Esta comParáção foi realizada por meio da utilização da equação desenvolvida por Gresens (1967). Devido à grande variação do fator volume optou-se por utilizar o fator médio do $\mathrm{TiO}_{2}$ correspondente a 1,0199 , o que significa que a alteração se verificou com um aumento de $2 \%$ do volume. Evidências petrográficas sugerem fortemente que o Ti tenha ficado imóvel durante o processo de alteração dos minerais máficos, permanecendo como titanita esquelPará e ilmenita, tal como já descrito por Ferreira Filho (1985), Sachs (1993) e Althoff Pará. (1994).

Os cálculos mostraram que a perda mais significativa foi de $\mathrm{CaO}$ (até $-6,60 \mathrm{~g}$ por cada $100 \mathrm{~g}$ de amostra), seguida do $\mathrm{Al}_{2} \mathrm{O}_{3}(-1,88 \mathrm{a}$ $-3,52 \%), \mathrm{K}_{2} \mathrm{O}(-0,80 \%)$ e $\mathrm{Rb}$ (até $\left.-24,34 \%\right)$. Os ganhos mais importantes corresponderam $\mathrm{SiO}_{2}(+2,88 \mathrm{a}+7,65 \%), \mathrm{MgO}(+1,16 \mathrm{a}+0,87 \%)$ e U $(+7,91$ a $9,13 \%)$. O Fe não foi muito móvel durante o processo de cloritização, tendo sido registrada uma perda média de $1,3 \%$. O ganho de $\mathrm{Si}$ e a perda de $\mathrm{Ca}$ estão de acordo com a silicifícação e albitização observadas.

INCLUSÕES FLUIDAS Foram estudados grãos de quartzo associados tanto com a assembléia mineral do granófiro anfibolítico como aquela do granófiro clorítico. No quartzo observam-se pequenas inclusões fluidas de tipos variados e que fornecem algumas informações interessantes sobre o fluido mineralizante e suas condições físicoquímicas. As amostras estudadas foram cuidadosamente escolhidas, e são representativas das duas assembléias acima citadas.

Tipos de Inclusões Fluídas Dois tipos principais de inclusões foram descritas no quartzo hidrotermal do granófiro, associado com a calcopirita que contém o ouro. $\mathrm{O}$ tipo $\mathrm{S}$, com diversas espécies de sólidos de saturação e/ou acidentais; e o tipo L, aquosa bifásica, ambos provavelmente primários ou pseudo-secundários. São inclusões de formas poligonais, irregulares, com tamanhos em geral inferiores a $10 \mathrm{jm}$. O tipo S normalmente apresenta uma distribuição aleatória, enquanto o tipo L tende a ocorrer em trilhas largas, irregulares ou, menos comumente, em grupos de distribuição aleatória, por vezes associadas com o tipo S. De acordo com os tipos de sólidos presentes e com os dados microtermométricos podem ser individualizadas subdivisões em $\mathrm{S}, \mathrm{S}_{2}, \mathrm{~L}_{1}$ e $\mathrm{L}_{2}$.

Subtipo $\mathbf{S}_{\mathbf{1}}$ (granófiro anfibolítico): Inclusões fluidas multifásicas precoces, compostas por água líquida, fase vapor e sólidos como halita cúbica, silvita (cubos menores) e, provavelmente, óxidos de ferro vermelhos e carbonato, junto com algumas fases não identificadas. Estes sólidos nem sempre ocorrem associados na mesma inclusão. O subtipo $\mathrm{S}_{1}$ é encontrado principalmente associado com o granófiro anfibolítico.

Subtipo $\mathbf{S}_{\mathbf{2}}$ (granófiro clorítico): Inclusões fluidas multifásicas precoces, compostas por água líquida, fase, vapor e um ou dois sólidos: halita cúbica e provavelmente $\mathrm{CaCl}_{2}$. E interessante notar a virtual ausência de oxido de ferro vermelho muito raro nestas inclusões $\mathrm{S}_{2} \mathrm{do}$ granófiro clorítico, e mais comuns no quartzo associado ao granófiro anfibolítico (Subtipo $\mathrm{S}_{1}$ ).

Subtipo $\mathbf{L}_{1}$ (granófiro clorítico): Inclusões fluidas bifásicas aquosas, tardias e por vezes aparentemente posteriores aos tipos S, com salinidade em torno de $10 \%$ eq. peso $\mathrm{NaCl}$. Encontradas somente nas amostras cloritizadas.

Subtipo $\mathbf{L}_{2}$ (granófiro anfibolítico e clorítico): Inclusões fluidas bifásicas aquosas, tardias, com uma clara dissolução de um hidrato por volta de $-26,0^{\circ} \mathrm{C}$. Este tipo muitas vezes está associado com os dois subtipos $\mathrm{S}$, no quartzo associado às duas Parágêneses, seja com anfibólio ou clorita.

Deve-se ressaltar também, a grande variação no grau de preenchimento dos supostos minerais de saturação nos dois subtipos $\mathrm{S}_{1}$ e $\mathrm{S}_{2}$, onde os sólidos podem ocupar quase toda a cavidade da inclusão variando gradativãmente até proporções ern torno de $15 \%$. Eventualmente no mesmo grupo, pode ser observada essa diversidade do grau de preenchimento, e também uma variação no número de sólidos presentes. Isto é, ao lado de uma inclusão multifásica, pode ocorrer uma trifásica e/ou bifásica do subtipo $\mathrm{L}^{\wedge}$. Este fenômeno pode estar ligado a estrangulamento ("necking down") das inclusões ou mais provavelmente a um fluido mineralizante original heterogêneo. Neste último caso a maioria dos sólidos seria acidental. Como será descrito mais adiante isto se reflete numa grande variação de temperaturas de homogeneização.

Microtermometria TIPOS $\mathrm{S}$ No subtipo $\mathrm{S}_{2}$ (associado ao granófiro clorítico) pôde-se observar a homogeneização total (TH) de diversas inclusões variando de 150 até $430^{\circ} \mathrm{C}$ (Fig. 12). As temperaturas de dissolução da halita sugerem salinidade muito alta, de até $40 \%$ eq. peso $\mathrm{NaCl}$. Em primeiro lugar ocorre o desaparecimento da fase vapor por volta de 100 a $130^{\circ} \mathrm{C}$, e depois o desaparecimento das fases sólidas. Por outro lado foram obtidas poucas medidas de temperaturas de homogeneização total nas inclusões multifásicas (subtipo $\mathrm{S}_{1}$ ), associadas ao quartzo do granófiro anfibolítico, em torno de $200^{\circ} \mathrm{C}$. Na maioria das inclusões medidas, algumas das fases sólidas simplesmente não desapareceram mesmo quando aquecidas até $500^{\circ} \mathrm{C}$. Muitas vezes essas inclusões crepitararn em altas temperaturas, acima de $350^{\circ} \mathrm{C}$ até $500^{\circ} \mathrm{C}$, indicando altas temperaturas mínimas de formação Pará o subtipo $\mathrm{S}_{1}$

TIPOS $L$ Os dois subtipos $\mathrm{L}$ apresentaram temperaturas de homogeneização total na fase líquida dentro da mesma faixa de $100 \mathrm{a} 160^{\circ} \mathrm{C}$, 


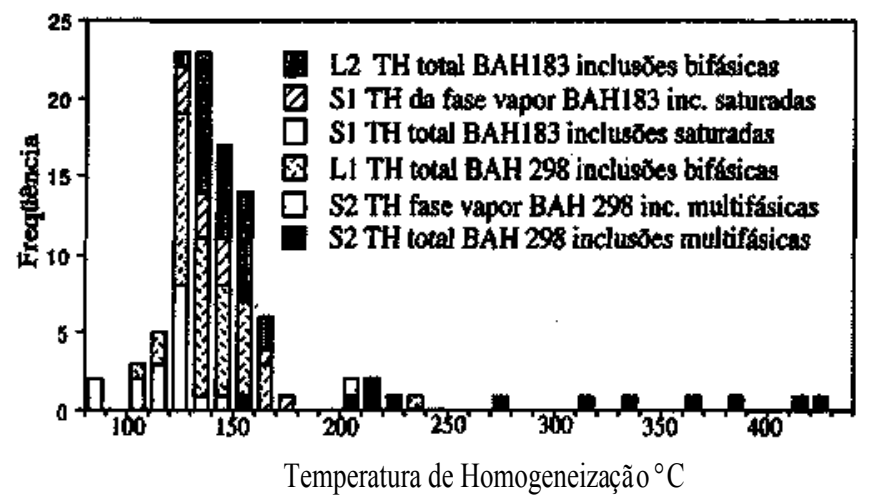

Figura 12 - Histograma apresentando a distribuição da temperatura de homogeneização nos diversos tipos de inclusões fluidas. Notar que nas inclusões saturadas são apresentadas as temperaturas de homogeneização da fase vapor e total (dos sólidos de saturação).

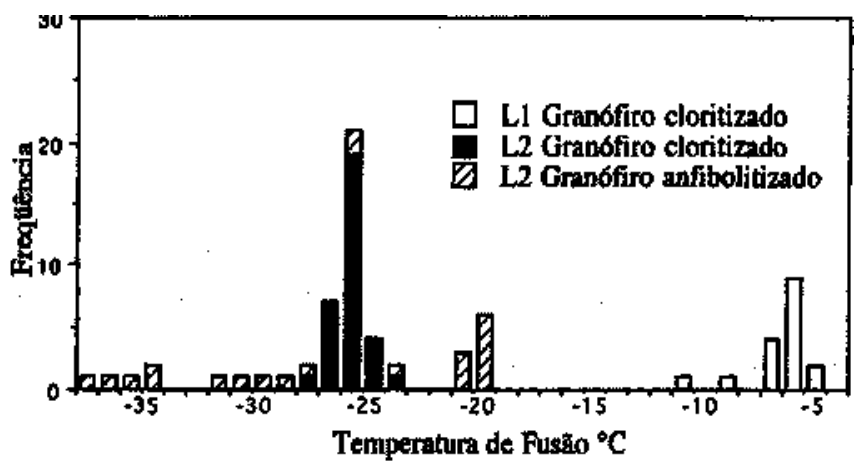

Figura 13 - Histograma apresentando a distribuição da temperatura de fusão nos diversos tipos de inclusões fluidas.

e equivalentes à temperatura de desaparecimento da fase vapor das inclusões multifásicas $\left(100 \mathrm{a} 130^{\circ} \mathrm{C}\right)$. A moda da TH total do tipo L é de 130 a $140^{\circ} \mathrm{C}$ e a moda da temperatura de desaparecimento das fases vapor dos tipos $\mathrm{S}$ é um pouco mais baixa, de 120 a $130^{\circ} \mathrm{C}$ (Fig. 12).

A temperatura de fusão do gelo do Subtipo $\mathrm{L}_{1}$ variou de -5 a $-7^{\circ} \mathrm{C}$ correspondendo a salinidade em torno de $10 \%$ eq. peso $\mathrm{NaCl}$, sem formação de hidrato e eutético em torno de $-22^{\circ} \mathrm{C}$. O subtipo $\mathrm{L}_{2}$ foi caracterizado por apresentar o início da fusão (eutético) em temperaturas inferiores a $-40^{\circ} \mathrm{C}$, dissolução de um hidrato por volta de $-26^{\circ} \mathrm{C}$ nas inclusões do quartzo associ- ado com o granófiro clorítico, e variando de -20 a -37 no caso das inclusões do subtipo $L_{2}$ associadas ao granófiro anfibolítico (Fig. 12). Em todos esses casos, após a dissolução do hidrato, é bem visível a presença de um outro sólido incolor (gelo ou outro hidrato) cuja fusão, lenta e gradativa demais, não foi possível determinar apesar dos esforços envidados, razão pela qual não se conhece a salinidade destas inclusões. A depressão das temperaturas do eutético abaixo de $-40^{\circ} \mathrm{C}$ sugere a presença de outros sais, além de $\mathrm{NaCl}$, como por exemplo $\mathrm{CaCl}_{2}$ (Fuzikawa 1985, Althoff Pará. 1994). Trabalhos de Zang (1993) em microscopia eletrônica de varredura determinaram, em amostras equivalentes, a presença de $\mathrm{CaCl}_{2}$.

Althoff Pará. (1994) estudando o quartzo de venulações da área do Igarapé Bahia descrevem os mesmos dois tipos principais de inclusões fluidas e de resultados microtermométricos.

Discussão dos dados das inclusões fluidas A figura 14 é um diagrama de temperatura de homogeneização versus temperatura de fusão, mostrando três campos onde, embora as TH estejam aproximadamente na mesma faixa, as temperaturas de fusão do gelo e dissolução de hidratos permitem seParár os fluidos relacionados ao quartzo do granófiro anfibolítico daquele do quartzo do granófiro clorítico. Embora rara, a existência de inclusões do tipo $S_{1}$ e $L_{2}$ no quartzo do granófiro cloritízado poderia representar resquícios do fluido de mais alta temperatura responsável pela formação do anfibólio. A tendência vertical n. 3 (granófiro clorítico) e, de maneira mais grosseira, a disposição dos grupos 1 (do granófiro anfibolítico) e 2 (do granófiro clorítico) sugerem uma queda de temperatura (Fig. 14).

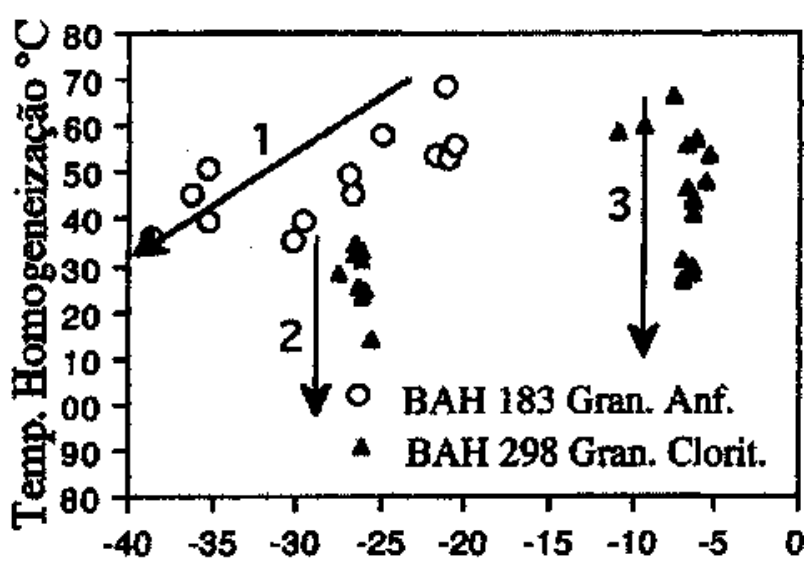

Temperatura de Fusão ${ }^{\circ} \mathrm{C}$

Figura 14 - Diagrama de variação da temperatura e salinidade em função das mudanças de ocorridas no sistema hidrotermal.

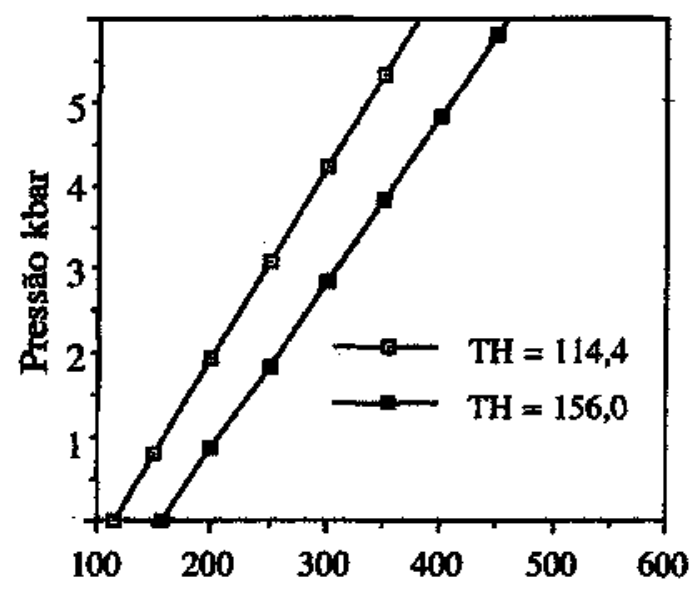

\section{Temperatura ${ }^{\circ} \mathrm{C}$}

Figura 15 - Isócoras construidas com a menor e a maior temperatura de homogeneização das inclusões fluidas do tipo L2, programa MacFlinCor, (Brown \& Hageman 1 994). Este diagrama permite supor pressões deformação (trapping) variando de 3,5 a 2,2 kbar.

As temperaturas de homogeneização mais altas $\left(300-430^{\circ} \mathrm{C}\right)$ poderiam corresponder às mais altas temperaturas atingidas na região do corpo mineralizado do Igarapé Bahia, e representadas pela assembléia hornblenda-actinolita e oligoclásio. A cloritização generalizada teria ocorrido em torno de $270^{\circ} \mathrm{C}$, após uma queda de temperatura, conforme sugerido respectivamente pelo geotermômetro da clorita (Lindenmayer \& Laux, em preParáção) e pela tendência 3 da figura 14. As temperaturas de homogeneização das inclusões bifásicas do subtipo L, são temperaturas mínimas de formação (trapping) que permitem a construção de isócoras e inferir pressões de formação entre 2 e 3,5 kbars (Fig. 15). As amplas variações de temperatura dos tipos S e L poderiam ser explicadas por um fluido original heterogêneo ou por estrangulamento (necking down) como acima sugerido, mas também poderiam ser resultado de uma reação contínua entre os fluidos hidrotermais e a encaixante granofírica, durante a queda de temperatura $\mathrm{e}$ precipitação do proto-minério.

ALTERAÇÃO HIDROTERMAL As transformações minerais de mais alta temperatura que ocorreram na área da Mina de Au do Igarapé Bahia formaram a associação meta-mórfica hornblenda-actinolita, biotita, junto com oligoclásio, a partir dos basaltos e da intrusão granofírica. Esta assembléia indica temperaturas superiores a $320^{\circ} \mathrm{C}$ (Spear 1993) e poderia ser representada pelas temperaturas de 350 a $500^{\circ} \mathrm{C}$ dadas pelas de crepitação das inclusões fluidas do tipo $\mathrm{S}_{2}$.

Essa assembléia é observada como relíquia, em zonas localizadas da intrusão granofírica, podendo ser resultante tanto de um processo metamórfico quanto de alteração hidrotermal. Ela é aqui considerada como metamórfica por ser sen- sivelmente menos hidratada do que a 
assembléia que a sucede. Esta Parágênese foi transformada na associação clorita-albita-carbonato-quartzo, dominante na área estudada, através de alteração hidrotermal, conforme a reação abaixo:

$\mathrm{Ca}_{2}(\mathrm{Mg}, \mathrm{FeO})_{5} \mathrm{Si}_{8} \mathrm{O}_{22}(\mathrm{OH})_{2}+1,5$ (Na.Ca) $\mathrm{Al}_{2} \mathrm{Si}_{2} \mathrm{O}_{5}+0,25 \mathrm{H}_{2} \mathrm{O}+$ $5,5 \mathrm{H}+==(\mathrm{Fe}, \mathrm{Mg})_{5} \mathrm{Si}_{3} \mathrm{Al}_{2} \mathrm{O}_{10}(\mathrm{OH})_{8}+\mathrm{NaAlSi}_{3} \mathrm{O}_{8}+5 \mathrm{SiO}_{2}+2,5 \mathrm{Ca}^{2}+$ $+0,5 \mathrm{Na}++0,2 \mathrm{O}_{2}(1)$

Se a intrusão granofírica, colocada na base do pacote sedimentar, estivesse na época, em posição horizontal, ela poderia ter funcionado como uma barreira impermeável Pará a circulação dos fluidos, cujo escape repentino teria provocado a brechação, fraturamento, e venulação semelhante ao modelo de Sibson (1990). A mineralização encontrada na área de Águas Claras, situada a leste (Barros Pará. 1994), poderia também ser explicada por um modelo semelhante.

Os fluidos hidrotermais mineralizantes circularam pelas fraturas, reagindo com as rochas adjacentes,- ao mesmo tempo em que a temperatura do sistema hidrotermal diminuía, o que deve ter provocado a grande faixa de variação das temperaturas de homogeneização das inclusões fluidas multifásicas no quartzo, aqui descritas. A cloritização generalizada ocorreu a uma temperatura de cerca de $270^{\circ} \mathrm{C}$, estimada tanto pelo geotermômetro da clorita (Lindenmayer \& Laux, em preParáção), como através da temperatura de homogeneização de inclusões fluidas.

Os fluidos responsáveis pela alteração deveriam ser ácidos, de acordo com a reação apresentada acima. Eles eram também salinos, o que é atestado pela presença de inclusões fluidas altamente salinas (até $40 \%$ eq. peso $\mathrm{NaCl}$ ) encontradas. Esses fluidos, portadores de altas concentrações de $\mathrm{Cl}$, teriam também favorecido a deposição de $\mathrm{SiO}_{2}$ como quartzo na rocha, de acordo com os dados experimentais de Popp \& Franz (1979).

Inicialmente a $\mathrm{P}_{\mathrm{CO} 2}$ e $\mathrm{P}_{02}$ devem ter sido suficientemente baixas Pará serem tamponadas pelas rochas, o que é demonstrado pela formação de siderita e hematita, em quantidades subordinadas, associadas a clorita e albita.

Com o aumento da $\mathrm{P}_{\mathrm{CO} 2}$ no fluido, possivelmente a partir da redução do $\mathrm{H}^{+}$, proveniente das reações de hidrólise (1), e com o abaixamento da temperatura do sistema, a calcita preci- pitou em veios, em zonas de cisalhamento, formando os calei- ta-clorita-xistos, e na brecha hidráulica, utilizando os cátions $\mathrm{Ca}^{++} \mathrm{e} \mathrm{Sr}^{++}$, em solução e previamente removidos do plagioclásio e do anfibólio. Junto com a calcita concentraram-se também os ETR, o F e o $\mathrm{Cl}$. A sílica, também lixiviada das rochas máficas, durante a hidrólise dos silicatos de mais alta temperatura, precipitou junto com a calcita nos veios tardios, formados nos estágios finais de alteração. Num estágio anterior, os fluidos enriquecidos em $\mathrm{SiO}_{2}$, provocaram também a silicificação seletiva do plagioclásio, descrita na intrusão granofírica.

Após a hidrólise (1), os fluidos tornaram-se mais alcalinos, possivelmente promovendo a solubilização do $\mathrm{Au}$, que deve ter sido transportado junto com os mParás, sob forma de complexos de $\mathrm{Cl}$ ou $\mathrm{S}$. Como o Au se encontra associado á calcopirita, sua precipitação deve ter sido controlada pelas mesmas condições que propiciaram a precipitação dos sulfetos. Assim, se seu transporte se verificou como complexos de $\mathrm{Cl}$ ou tiocomplexos, a diminuição de temperatura, sugerida pelas inclusões fluidas, associada ao abaixamento da atividade do S (devido a precipitação da calcopirita e pirita), pode ter controlado sua precipitação na estrutura destes sulfetos. (Mycroft Pará. 1995).

Os fluidos responsáveis pelo processo de alteração e pela mineralização eram ricos também em ETRL, além de $\mathrm{Cu}, \mathrm{Ag}, \mathrm{Au}, \mathrm{Mo}$.

$\mathrm{O}$ enriquecimento em ETR e flúor nos calcita-clorita-xistos, ETRL e U na intrusão granofírica e na formação ferrífera, as boas correlações positivas encontradas entre $\mathrm{Mo}-\mathrm{Pb}$ e $\mathrm{Mo}-\mathrm{Ag}$, além da presença de molibdenita e fluorita nas rochas granofíricas e da alta salinidade dos fluidos (até $40 \%$ eq. $\mathrm{NaCl}$ ), encontrados nas inclusões do tipo $\mathrm{S}_{2}$ do granófiro cloritico, indicam que este sistema hidrotermal se instalou sob influência de fluidos onde rochas crustais, provavelmente graníticas, tiveram um papel preponderante.

Fluidos hidrotermais, ricos em $\mathrm{CO}_{2}, \mathrm{~F}$ e $\mathrm{Cl}$ podem remobilizar ETR (Kerrich \& Freyer 1979), tal como se verificou na área. Isto pode ser observado pelo enriquecimento em ETRL exibido pela intrusão granofírica e pela formação ferrífera, e pelo aumento do conteúdo total das ETR verificado nos calcita-clorita-turmalina-xistos em relação ás rochas dos quais são provenientes por alteração, como o gabro granofírico e o metabasalto.

A existência de fluorita e molibdenita em diversos grani tos anorogênicos de idade proterozóica média que ocorrem na região, tais como Cigano, Salobo, Pojuca e Carajás, faz com que estes granitos sejam bons candidatos Pará a fonte destes sistemas hidrotermais.

O sistema hidrotermal instalado teve provavelmente grandes proporções, pois provocou a alteração generalizada das rochas, juntamente com um aumento de volume de $2 \%$.

CONCLUSÕES No extremo sul da Mina do Igarapé Bahia (linha LT 00), arenitos conglomeráticos e arenitos gros- sós ocupam o topo da seqüência vulcano-sedimentar. Eles pré- dominam a SW e dão lugar em direção NE, a um pacote de ritmitos, que indicam aprofundamento da bacia neste sentido.

Os ritmitos são provenientes principalmente de basaltos toleiíticos, embora sejam mais enriquecidos em U, ETRL, K e Rb do que a média das rochas sedimentares comuns, tanto arqueanas como proterozóicas, mostradas por Condie (1993), Taylor \& McLennan (1985) e McLennan (1982).

$\mathrm{Na}$ base do pacote sedimentar encontra-se uma intrusão gabróica de textura média a grossa, granofírica, cujos contatos encontram-se balizados por zonas de brecha hidráulica e xistos carbonáticos.

Metabasaltos encontram-se sotopostos à intrusão granofírica.

Há intensa alteração hidrotermal associada à mineralização sulfetada. Ela é representada pela assembléia clorita-quartzo-albitacarbonato (conforme já descrito por Ferreira Filho (1985)), presente em todas as rochas, com exceção de um dique de diabásio que corta a unidade sedimentar e pós-data a mineralização.

Tal como os ritmitos, todas as rochas alteradas são enriquecidas em ETRL, U, F e Cl.

Foi individualizada uma fase metamórfica, nos gabros granofíricos, anterior a alteração hidrotermal.

A alteração hidrotermal no gabro granofírico se verificou com um aumento de volume de $2 \%$ nas rochas.

Os cálculos geoquímicos de balanço de massa mostraram que a perda mais significativa foi de $\mathrm{CaO}$ (até $-6,60 \mathrm{~g}$ por cada $100 \mathrm{~g}$ de amostra), seguida do $\mathrm{A}_{2} \mathrm{O}_{3}(-1,88 \mathrm{a}-3,52 \%), \mathrm{K}_{2} \mathrm{O}(-0,80 \%)$ e $\mathrm{Rb}$ (até $-24,34 \%)$. Os ganhos mais importantes corresponderam $\mathrm{SiO}_{2}(+2,88$ a $+7,65 \%), \mathrm{MgO}(+1,16$ a $+0,87 \%)$ e U $(+7,91$ a $9,13 \%)$. O Fe não foi muito móvel durante o processo de cloritização, tendo sido registrada uma perda média de $1,3 \%$.

A mineralização sulfetada, no extremo sul do corpo mineralizado da Mina do Igarapé Bahia, encontra-se concentrada principalmente na zona de brechas hidráulicas.

A mineralização formada por calcopirita e pirita, com calcosita e covelita subordinadas, constitui os dois tipos principais de minério primário que são o disseminado e o venular, conforme já descrito por Ferreira Filho (1985), Sachs (1993) e Althoff Pará. (1994) O Au encontra-se associado a alguns cristais de calcopirita (Bocalon 1996).

Os fluidos responsáveis pelo processo de cloritização generalizada, e pela mineralização, eram ricos em $\mathrm{CO}_{2}, \mathrm{U}$ e ETR, além de $\mathrm{Cu}, \mathrm{Ag}$, $\mathrm{Au}, \mathrm{Mo}$. As correlações entre $\mathrm{Mo}-\mathrm{Pb}=0,913 ; \mathrm{Ag}-\mathrm{Mo}=0,794$ e Ag-Pb $=0,782$ sugerem fonte comum Pará estes mParás.

$\mathrm{O}$ enriquecimento em ETR, $\mathrm{F}$ e $\mathrm{Cl}$ nos xistos carbonáticos, ETRL e U na intrusão granofírica e ETRL e U na formação ferrífera, juntamente com as boas correlações positivas encontradas entre $\mathrm{Mo}-\mathrm{Pb}$ e Mo-Ag, e a alta salinidade encontrada nas inclusões fluidas (até $40 \%$ eq. peso $\mathrm{NaCl}$ ), indicam que este sistema hidrotermal se instalou sob influência de fluidos magmáticos, de forte contribuição crustal, provavelmente granítica. Enriquecimento semelhante ocorre no depósito de $\mathrm{Cu}$ (Au-Mo) do Salobo, associado ao granitóide anorogênico jovem (Lindenmayer Pará. 1995) e também no depósito de $\mathrm{Cu}(\mathrm{Zn})$ do Pojuca.

Estes dados sugerem fortemente que a província mineral da região da Serra dos Carajás deva grande parte de sua riqueza mineral à grandes sistemas hidrotermais, associados à colocação das intrusões graníticas anorogênicas, no Meso-Proterozóico.

Agradecimentos À Companhia Vale do Rio Doce pelo acesso aos dados, hospedagem na área e utilização da microssonda eletrônica do laboratório da SUTEC, em Minas Gerais. À Docegeo pelo apoio de campo, sem o qual o trabalho não poderia ter sido desenvolvido. Este trabalho é parte integrante do projeto PADCT-FINEP "Caracterização de Minérios e Rejeitos de Depósitos Minerais Brasileiros" coordenado pelo Prof. Dr. Onildo J. Marini, ao qual os autores são muito gratos. Parte dos recursos são provenientes da FAPERGS, processo n. ${ }^{\circ}$ 93/017225-1. 


\section{Referências}

Althoff, A.M.R., Villas, R.N.; Giuliani, G.A. 1994. Mineralização cuprífera da área Bahia, Serra dos Carajás (PA): Evolução dos fluidos hidrotermais e modelo mParáogenético. Geochimica Brasiliensis, 8:135-155.

Angélica, R.S.; Costa, M.L.; Lenharo, S.L.R.; Põllmann, H. 1996. Ocorrência de uraninita associada com o ouro do Igarapé Bahia, Carajás, Pará. In: Simpósio de Geologia da Amazônia, 5, Belém, 1996. Boletim de Resumos Expandidos. Belém, SBG. p. $152-155$.

Alves, F. \& Brito, O. 1996. Com novas minas a Vale pode produzir 18 t. Brasil Mineral. 141:32-35.

Araújo, O.J.B.\&Maia,R.G. 1991. Programa Levantamentos Geológicos Básicos do Brasil. Programa Grande Carajás. Serra dos Carajás, Folha SB.22-Z-A. Brasília DNPM/CPRM. 164 p.

Bailey, S.W. 1988. Chlorites: Structure and crystal chemistry. In: Hydrous Phyllosilicates (exclusive of micas). Reviews in Mineralogy, 19. Mineralogical Society of America. p. $348-403$

Barros, C.E.M. \& Dali'Agnol, R. 1993. Geochemistry of the Estrela gneiss, Carajás region, state of Pará: an Example of A-type Archean magmatism. In: Workshop Magmatismo Granítico e Mineralizaçòes Associadas, Rio de Janeiro, 1993. Boletim de Resumos Expandidos. Recife, UFPE. p. 58-59.

Barros, C.E.M.; Dall'Agnol, R.; Soares, A.D.V.; Dias, G.S. 1994. Metagabros de Águas Claras, Serra dos Carajás: Petrografia, geoquímica e transformações metamórfico-hidrotermais. Acta Geológica Leopoldensia, 40:1-70.

Beisiegel, V.R.; Bernardelli, A.L.; Drummond, N.F.; Ruff, A.W.; Tremaine, J.W. 1973. Geologia e recursos minerais da Serra dos Carajás. Revista Brasileira de Geociências, 3:215- 242.

Bocalon, V.L.S. 1997. Caracterização da Mineralização Primária de Cu-Au da Mina do Igarapé Bahia, Carajás, Pará. 120 p. (Dissertação de Mestrado, UNISINOS).

Brown, P. E. \& Hagemann, S. G. 1994. MacFlinCor: a computer program for fluid inclusion data reduction and manipulation. In: De Vivo, B. \& Frezzotti, M. L. (Ed.) Fluid Inclusions in minerais: methods and applications. Virgínia Tech, Blaksburg. p. 231 -250 .

Condie, K.C. 1981. Archean Greenstone Belts. Developments in Precambrian Geology 3. Amsterdam, Elsevier, $434 \mathrm{p}$.

Condie, K.C. 1993. Chemical composition and evolution of the upper continental crust Contrasting results from surface samples and shales. Chemical Geology, 104:1-37.

Costa, M.L. \& Angélica, R.S. 1996. Two generations of laterite profile in the Amazon region and their ore potential. In: Simpósio de Geologia da Amazônia, 5. Belém, 1996. Boletim de Resumos Expandidos. Belém, SBG. p. 269.

Dias, G.S.; Macambira, M.J.B; Dall'Agnol, R.; Soares, A.D.V.; Barros, C.E.M. 1996. Datação de zircões de sill de metagabro: comprovação de idade arqueana da Formação Águas Claras, Carajás - Pará. In: Simpósio de Geologia da Amazônia, 5 , Belém, 1996. Boletim de Resumos Expandidos. Belém, SBG. p. 376-379.

DOCEGEO. 1988. Revisão Litoestratigráfica da Província Mineral de Carajás. In: Congresso Brasileiro de Geologia, 35. Belém, 1988. Anexos aos Anais. Belém, SBG. p. 11-54.

Ferreira Filho, C.F. 1985. Geologia e Mineralizaçòes Sulfetadas do Prospecto Bahia, Província Mineral de Carajás. 112 p.(Dissertação de Mestrado, Universidade de Brasília),

Fuzikawa, K. 1985. Inclusões fluidas: Métodos usuais de estudo e aplicações. In: Contribuições à Geologia e à Petrologia. SBG - Núcleo de Minas Gerais (SBGM) p. 29-44.

Gibbs, A.K.; Wirth, K.R.; Hirata, W.K.; Olszewski Jr., W.J. 1986. Age and composition of Grão Pará Group volcanics, Serra dos Carajás. Revista Brasileira de Geociências. 16:201-211

Gresens, R. L. 1967. Composition-volume relationships of metasomatism. Chemical Geology 2:47-65.

Hirata, W.K.; Rigon, J.C.; Kadekaru, K.; Cordeiro, A.A.C. \& Meireles, E..M. 1982. Geologia Regional da Província Mineral de Carajás. In: Simpósio de Geologia da Amazônia, 1, Belém, 1982. Anais... Belém, SBG. v. 1, p. 100-110.

Kerrich, R. \& Freyer, B.J. 1979. Archean precjous mPará hydrothermal systems Dome Mine, Abitibi Greenstone Belt II. REE and oxygen isotope relations. Canadian Journal of Earth Science, 16:440-458.

Laskowski, N. \& Krõner, A. 1985. Geochemical characteristics of Archean and late Proterozoic to Palaeozoic fine-grained sediments from Southern África and significance for the evolution of the continental crust. Geologische Rundschau, $74: 1-9$.
Lindenmayer, Z.G. 1990. Salobo Sequence, Carajás, Brazil: Geology, Geochemistry and Metatnorphism. 406 p. (Doctor of Philosophy Thesis. Department of Geology of the University of Western Ontario, Canada).

Lindenmayer, Z.G.; Laux, J.H.; Vieiro, A.C. 1995. O papel da alteração hidrotermal nas rochas da Bacia Carajás. Boletim do Museu Paráense Emilio Goeldi, Série Ciências da Terra, 7:125-145.

Lindenmayer, Z.G. \& Laux, J.H. (em preParáção) ComParáção entre os processos de alteração hidrotermal das intrusões granofíricas da mina de Au do Igarapé Bahia e do Depósito Ferrífero de S11, Serra Sul^ ${ }^{\wedge}$ Serra de Carajás, Pará. (Submetido à Revista Geochimica Brasiliensis)

Machado, N.; Lindenmayer, Z.; Krogg, T.E.; Lindenmayer, D. 1991. U - Pb geochronology of Archean magmatism and basement reactivation in the Carajás área, Amazon shield, Brazil. Precambrian Research., 49:1-26.

McLennan, S.M. 1982. On the geochemical evolution of sedimentary rocks. Chemical Geology. 37:335-342.

Meirelles, M.R. \& Dardenne, M.A. 1991. Vulcanismo basáltico de afinidade shoshonítica em ambiente de arco arqueano, Grupo Grão-Pará, Serra dos Carajás-Pará. Revista Brasileira de Geociencias, 21:41-50.

Miyashiro, A. 1974. Volcanic rock series in island ares and active continental margins. American Journal of Science, 274:321-355.

Mycroft, J.R.; Bancroft, G.M.; Mclntyre, N.S.; Lorimer, J.W. 1995. Spontaneous deposition of gold on pyrite from solutions containing $\mathrm{Au}$ III and Au I chlorides. Part I: A surface study. Geochimica et Cosmochimica Acta. 59:3351-3365.

Nakamura, N. 1974. Determination of REE, Ba, Fe, Mg, Na and K in carbonaceous and ordinary chondrites. Geochimimica et Cosmochimica Acta, 38:757-775.

Popp, R. K. \& Frantz, D. J. 1979. Mineral solution equilibria - II. An experimental study on mineral solubilities and the thermodynamic properties of aqueous $\mathrm{CaCh}$ in the system CaO-SiCh-HaO-HCl. Geochimica et Cosmochimica Acta, 43:1777-1790.

Poty, B.; Leroy, J.; Jachimowicz, L. 1976. Un nouvel appareil pour Ia mesure dês températures sous lê microscope: 1'installation thermométrique Chaix Meca. Buli. Societé Francaise du Mineralogie. 99:182-186.

Ribeiro, A.M.\& Villas, R.N.N. 1986. Estudo microtermométrico em cristais de quartzo de veios hidrotermais da Seqüência Bahia, Carajás, Pará. In: Congresso Brasileiro de Geologia, 34, Goiânia, 1986. Anais... Goiânia, SBG. p. 1193-1204.

Sachs, L.L.B. 1993. O magmatismo associado ao depósito mineral cupro-aurífero do Igarapé Bahia, Carajás, PA, Brasil. 142p. (Dissertação de Mestrado, Universidade de Campinas).

Shelley, D. 1992. Igneous and Metamorphic Rocks Under the Microscope. Chapman \& Hall, $445 \mathrm{p}$.

Sibson, R.H. 1990. Fault and mechanics in relation to greenstone gold deposits. Conference on Greenstone Gold and Crustal Evolution, 9. Vai D'Or. p. 54-60.

Silva, G.G.; Lima, M.I.C.; Andrade, A.R.F.; Issler, R.S.; Guimarães, G. 1974. Projeto Radam. Geologia das Folhas SB-22 Araguaia e parte da SC-22 Tocantins. MME/DNPM, 143 p. (Boletim 4).

Souza, S.R.B.; Macambira, M.J.B.; Scheller, T. 1996. Novos dados geocronológicos Pará os granitos deformados do Rio Itacaiunas (Serra dos Carajás); implicações estratigráficas. In: Simpósio de Geologia da Amazônia, 5. Belém, 1996. Boletim de Resumos Expandidos Belém, SBG. p. 380-383.

Spear, F.S. 1993. Metamorphic Phase Equilibria andPressure-Temperature- Time Paths. Monograph. Mineralogical Society of America, $799 \mathrm{p}$.

Taylor, R.S. \& McLennan, S.M. 1985. The Continental Crust: Its Composition and Evolution. Blackwell Scientific Publications, $312 \mathrm{p}$.

Teixeira, J.B.T. \& Eggler, D.H. 1994. Petrology, geochemistry and tectonic setting of archean basaltic and dioritic rocks from the N4 Iron Deposit, Serra dos Carajás, Pará. Acta Geológica Leopoldensia, 40: 71-114.

Zang, W. \& Fyfe, W.S. 1993. A three stage genetic model for the Igarapé Bahia Lateritic Gold Deposit, Carajás, Brazil. Economic Geology, 88:1768-1779.

Zang, W. \& Fyfe, W.S. 1995. Chloritization of the hydrothermally altered bedrock at the Igarapé Bahia Gold Deposit, Carajás, Brazil. Mineralium Deposita, 30: 30-38.

Zang, W. 1993. Geochemistry and Mineralogy ofthe Igarapé Bahia Lateritic Gold Deposit, Carajás, Brazil. 416 p. (Doctor of Philosophy Thesis. Department of Geology of the University of Western Ontario, Canada).

Manuscrito A-938
Recebido em 05 de outubro de 1997

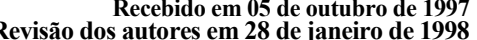
Revisão aceita em 30 de janeiro de 1998 